\title{
Need, frames, and time constraints in risky decision-making
}

\section{Adele Diederich $^{1}$ (1) $\cdot$ Marc Wyszynski $^{2}$ (1) $\cdot$ Stefan Traub $^{3}$ (1)}

Published online: 6 February 2020

(C) The Author(s) 2020

\begin{abstract}
In two experiments, participants had to choose between a sure and a risky option. The sure option was presented either in a gain or a loss frame. Need was defined as a minimum score the participants had to reach. Moreover, choices were made under two different time constraints and with three different levels of induced need to be reached within a fixed number of trials. The two experiments differed with respect to the specific amounts to win and the need levels. The $2 \times 2 \times 3$ design was a within-subject design. Data were evaluated on an overall and on a group level, the latter based on participants' stated risk preference and on revealed preferences (choice proportions) using cluster analysis across subjects. Overall, the results showed riskier behavior when the choice options were presented as losses as compared to gains (framing effect) and when the induced need was highest. Time limits enhanced the framing effect.
\end{abstract}

Keywords Need · Framing effect · Time constraints · Induced need · Reflection effect $\cdot$ Risky choice $\cdot$ Decision-making $\cdot$ Individual differences

Adele Diederich

a.diederich@jacobs-university.de

Marc Wyszynski

m.wyszynski@jacobs-university.de

Stefan Traub

stefan.traub@hsu-hh.de

1 Department of Life Sciences and Chemistry, Jacobs University Bremen, Campus Ring 1, 28759 Bremen, Germany

2 Department of Psychology and Methods, Jacobs University Bremen, Campus Ring 1, 28759 Bremen, Germany

3 Department of Economics, Helmut-Schmidt-University, Holstenhofweg 85, 22043 Hamburg, Germany 


\section{Introduction}

Apart from equality and equity, need has been identified as one of the main ingredients of 'empirically informed' pluralistic theories of justice (Sabbagh and Schmitt 2016; Konow 2001, 2003; Deutsch 1975). Need has been defined as an objective lack of resources that are necessary to maintain physiological and mental health, as relative deprivation, or as the incapability to partake in the commonly accepted activities of the community (for an interdisciplinary perspective on needs and need-based justice, see the contributions in the edited volume by Kittel and Traub 2020). Irrespective of its theoretical conception, need seems to serve as an important reference point for allocating resources.

For instance, in a questionnaire experiment, Schwinger and Lamm (1981) and Lamm and Schwinger (1983) showed that subjects allocated a significantly higher share of money to more needy persons even if they were responsible for their higher need. Utilizing Törnblom's (1988) classification framework for conflicting justice principles, Gamliel and Peer (2006) investigated the framing of justice judgments in different vignettes scenarios. They found significant framing effects with respect to the need principle for some of them. In health care resource allocation scenarios, Gamliel and Peer (2010) observed that need, equity, and tenure principles were evaluated to be fairer in positively framed situations (i.e., to deliver health care resources to certain patients) than negatively framed situations (i.e., not to deliver health care resources to other patients).

Little attention has been paid to need in the context of framing and risky decisions. Recently, Diederich et al. (2018) investigated need, defined as the number of people who were affected by a certain disease, i.e., in need of a treatment, in an Asian disease setting (Tversky and Kahneman 1981) with various diseases (unusual disease, leukemia, AIDS). They found (1) that when need was high, i.e., a large number of people were affected, the participant became more risk averse; and (2) more framing effects occurred when more people were affected by a disease. Note that the size of this moderation effect depended on the kind of disease.

In the current study, we examine the impact of need in the context of risky gambles framed as gains or losses. We hypothesize that the level of need and the framing influences choice behavior. To be specific, for eliciting decisions, we offer simple games, the 'drosophila' of decision-making-under-risk research (cf. Lopes 1983, p. 137; Kahneman 2011, p. 270), with two choice options, one being a sure and the other a risky option. To investigate biases, we frame the sure option as either a gain or as a loss (Kahneman and Tversky 2000; Kühberger 1998; Tversky and Kahneman 1981). Need is induced in terms of a minimum requirement of points (converted to money) a person has to meet during a series of games for not being excluded from payoff. That is, the need threshold here resembles in a highly stylized way the minimum amount of money a person or household would need to make ends meet.

How would a rational decision-maker deal with need thresholds? Need may formally be introduced into the expected-utility framework by the Stone-Geary utility function (Geary 1950; Stone 1954), which is one of the workhorse models in 
the empirical economic literature to estimate consumer demand behavior. The socalled "linear expenditure system" derived from the maximization of a StoneGeary utility function can be split into two components (for details, see Deaton and Muellbauer 1980): first and foremost, the minimum consumption of each good has to be met. Second, after subtracting the subsistence income that is needed to buy the minimum quantities, the remainder of her income is spent according to her preferences. The minimum consumption levels are usually interpreted as indispensable to life and only consumption levels exceeding them create utility. Hence, under the null hypothesis of expected-utility maximization, we would expect a consistent decision-maker to become more risk seeking with increasing induced need, regardless of the frame. A general preference shift towards more risk seeking caused by need thresholds would also make the gain-loss framing effect less likely to occur.

Note that the results of the study by Diederich et al. (2018) contradict the predictions of the Stone-Geary utility framework with respect to the role of need in decision-making. This discrepancy may be due to the different definitions of need but may also be due to the different perspectives: in the Asian disease study, the participant makes decisions that affect other people's chance to survive, not his or her own. In the game, the outcome affects the decision-maker's own income. The Stone-Geary utility framework applies to the decision-maker's own need only.

Numerous empirical studies have shown that the required invariance of normative models such as expected utility theory (Von Neumann and Morgenstern 1947 ) is frequently violated. Description invariance has been challenged the most: people react to a particular choice in different ways depending on how it is presented (Kahneman and Tversky 2000; Tversky and Kahneman 1981). Losses and gains are interpreted with respect to a reference point (reflection effect) (Tversky and Kahneman 1981).

Another frame, rather in a loose sense, is different time constraints. Presenting identical choice options but constraining the decision time can produce preferences reversal and shifts (e.g., Diederich and Busemeyer 2006; Diederich 2003) or modify wording-induced framing effects (Diederich et al. 2018; Guo et al. 2017; Guo et al. 2015).

In summary, we expect a framing effect to occur when no need (control) is induced. This effect should be enhanced under short deadlines. With increasing induced need, the framing effect should disappear following Stone-Geary but should be moderated when interpreted as another reference point. Two experiments are reported with a slightly different setup. Due to some unexpected results of experiment 1, we recalibrated specific values in Experiment 2.

\section{Experiment 1}

Similar to De Martino et al. (2006), Guo et al. (2015), and Guo et al. (2017), the present study involved a game with two choice options. Participants had to choose between a sure option and a gamble, with the sure option presented in either a gain 
A

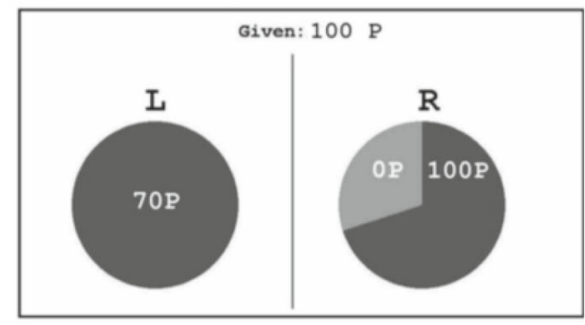

$\mathrm{B}$

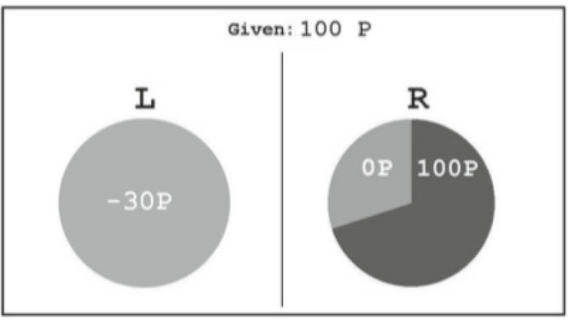

Fig. 1 Sample trial presentations for a gain frame (a) and a loss frame (b)

or a loss frame (Fig. 1). Two response limits were included and three different levels of induced need. Details are described next.

\subsection{Participants}

Nineteen undergraduate students from Jacobs University Bremen (13 female; age between 19 and 24 years; median 21 years) were recruited as voluntary participants. They received $6.00 €$ per hour for their participation (regardless of performance) and $0.001 €$ per point earned in the games. The experiment has been approved by the BIGSSS ethics committee. Participants gave their written informed consent prior to their inclusion in the study. They were screened for their ability to follow the experimental instructions and completed three sessions, spread over 3 days; a session lasted between 35 and 55 min.

\subsection{Materials and design}

For the test trials, four point amounts were selected: 25, 50, 75, and 100 . The values were identical to the study of De Martino et al. (2006). Four probabilities were selected to serve as the probability of winning the gamble: $0.3,0.4,0.6$, and 0.7 . The initial amounts and probabilities of winning the gamble were paired together to form 16 unique gambles. From these pairs, the sure option for each trial was created to match the expected value of the gamble, depending on framing. For instance, for an initial amount of 100 points and a winning gamble probability of 0.7 , the sure option would either be "Keep 70" (gain frame) or "Lose 30" (loss frame).

Note that in both frames, the gamble was identical, that is, they had the same expected value. Furthermore, the expected value of the gamble was identical to the amount received in the sure option.

The catch trials had non-equivalent sure and gamble options in which one option had a significantly larger expected value. Eight catch trials were constructed: four gain frame trials and four loss frame trials. The initial starting values for these trials were 25, 50, 75 and 100; the winning gamble probabilities were 0.3 and 0.7 . In half of these trials, the sure option had a higher expected value (starting value $\times 0.7$ ) than the gamble option (starting value $\times 0.3$ ). In the other half of the trials, the gamble option had a higher expected value (starting value $\times 0.7$ ) than the sure 
(starting value $\times 0.3)$ option. This results in 40 unique games (16 gain frame test games; 16 loss frame test games; 4 gain frame catch games; 4 loss frame catch games).

Within each block each game was presented twice in random order, resulting in 80 trials per experimental block.

The experiment consisted of three sessions, each session with four blocks of trials. Within each session, two different response time limits were included: the first and third blocks with $1 \mathrm{~s}$, and the second and fourth blocks with $3 \mathrm{~s}$.

In each experimental block, participants could attain any amount between 0 points (lose every gamble) and 5000 points (win every gamble). Across the sessions, three different levels of induced need, defined as the minimum points to be obtained during one block of trials, were applied with levels 0, 2500, and 3500 points. Zero points served as baseline control; in several test runs, 2500 points were reached in about $50 \%$ of the blocks and 3500 points were missed each time. If the participant met the required minimum score, the points earned during one block of trials were converted into money ( $0.001 €$ per point) and paid at the end of the experiment. If the participant did not reach the goal, no points were awarded. To summarize, the 2 frames (gain, loss) $\times 2$ time limits $(1 \mathrm{~s}, 3 \mathrm{~s}) \times 3$ needs $(0,2500,3500)$ design produced 12 experimental conditions. For all experimental factors, we use a withinsubject design which allows us to simultaneously test the effects of the different factors in the most transparent way (Diederich et al. 2018). One session consisted of four experimental blocks, two with a 1-s time limit and two with a 3-s time limit. 20 unique games (including catch trials) for each of the 2 frames and each of the 2 response time limits and each of the 3 needs with 4 replications per condition result in a grand total of 960 observations per participant.

\subsection{Apparatus}

Stimulus presentation and response registration were controlled by a standard computer running a 64bit Linux Mint (v. 17.3.) Cinnamon operating system with a standard 22" LCD wide-screen monitor (screen resolution: $1920 \times 1080$ pixels). The control software operated on Matlab ${ }^{\circledR}$ 2014a including the Psychophysics Toolbox version 3. The response device was a USB 2.0 controller with two buttons. The monitor display had a white background; the instruction text there was written in black with font 'Courier New' and font size 24 pt. Choice options were represented by grayscale representations of keeping an amount (represented by dark gray) and losing an amount (represented by light gray), as shown in Fig. 1; text there was written in white. The diameter of the pie charts representing the choice options was $250 \mathrm{px}$. The sure or the gamble option was randomly presented on the left or the right side. Available time for making a decision was indicated by eight vertical bars displayed at the bottom of the screen and removed one by one as a function of the preset time limits, i.e., the given time limit divided by eight. (see Fig. 2c). 

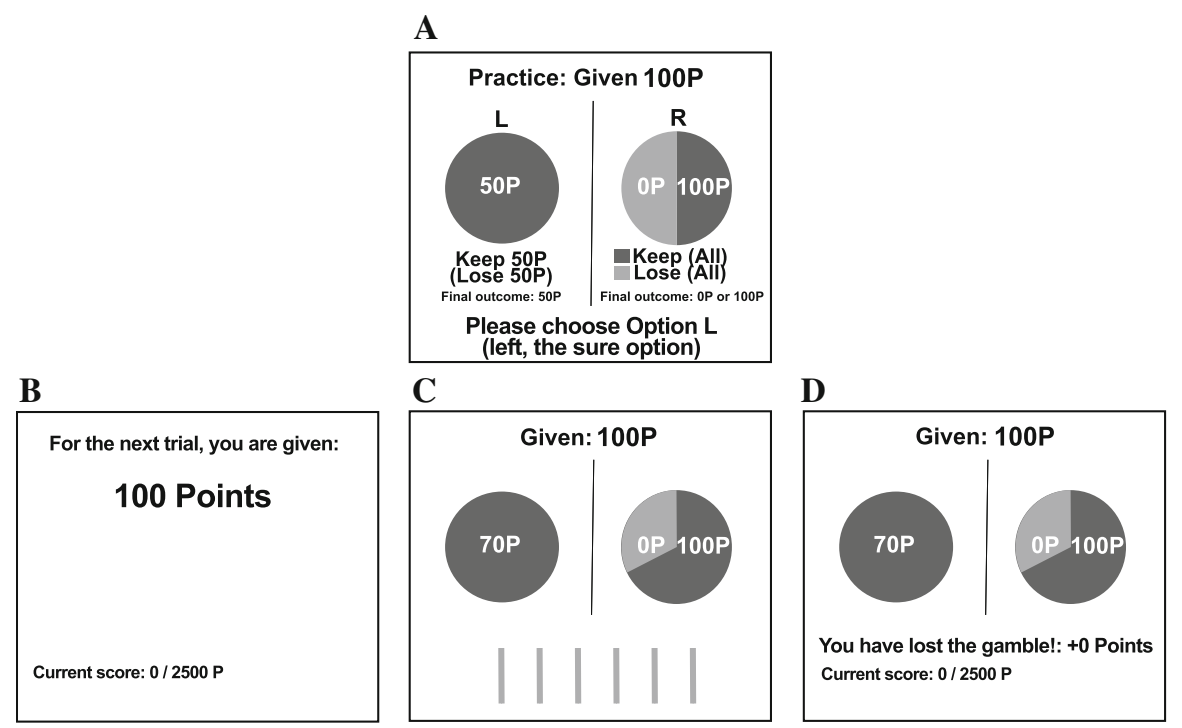

Fig. 2 Example of a guided practice trial (a) and time line for one trial in a gain frame (b-d). The screen displaying the initial amount given was presented for $2.5 \mathrm{~s}$ (b). It also displayed the induced need for the block of trials and the points reached so far. The screen displaying the game was presented for either $1 \mathrm{~s}$ or $3 \mathrm{~s}$, depending on the experimental condition (c). The bars below the pie charts indicate the available time for a particular trials (speed by which the bars were removed). The feedback screen (d) was presented for $2.5 \mathrm{~s}$, in which the points obtained in the current game, the accumulated points, and the need target were shown

\subsection{Procedure}

Each participant performed the three sessions on three different days. The three sessions differed with respect to the induced need $(0,2500,3500)$, pseudorandomized across days and participants. After reading the instructions, the participants completed three guided practice trials where they were told to select specific options (i.e., the gamble or sure option). After the guided practice, participants completed six trials practice where they could respond freely. In all guided practice trials and in the first two practice trials, the number of points to keep/lose when choosing the respective option was displayed and further explained beneath the pie charts indicating the probabilities (Fig. 2a). The legend faded away step by step during the practice trials. No time limits and no need points were applied in practice trials. This procedure was repeated at the beginning of each session (i.e., day). Participants were informed that they could not reach the points in the experimental trials by choosing the sure option only.

The experimental trials started with showing the amount of points given for that trial and the induced need, which was constant within one block of trials. In addition, the accumulated points up to that trial were also shown. The display lasted for $2.5 \mathrm{~s}$ (Fig. 2b). The subsequent screen showed the game and the time limit for that particular trial (Fig. 2c) and lasted for $1 \mathrm{~s}$ or $3 \mathrm{~s}$, depending on the experimental condition. A response had to be made within the given time limit. The last screen 
(Fig. 2d) provided feedback about the outcome of the current game, the points accumulated so far and the need target. It lasted for $2.5 \mathrm{~s}$. After offset of the screen, the next trial started.

After participants finished the last block of the experiments, they were given a short questionnaire on their individual risk behavior. The questionnaire is part of the "Sozio-Oekonomisches Panel 2009" (TNS Infratest Sozialforschung 2012), which is "(...) a wide-ranging representative longitudinal study of private households, located at the German Institute for Economic Research, DIW Berlin. Every year, there were nearly 11,000 households, and about 30,000 persons sampled by the fieldwork organization TNS Infratest Sozialforschung. (...) Some of the many topics include household composition, occupational biographies, employment, earnings, health and satisfaction indicators." (https://www.diw.de/en/diw_02.c.221178.en/ about_soep.html). This survey contains three questions on individual risk behavior. The questions are in Appendix 1. All items were measured on a scale from 0 to 5 with 0 for no willingness for taking risk and 5 for willingness to take high risk.

\subsection{Statistical methods}

Data were evaluated using descriptive statistics and cluster analyses. Autocorrelation was used to test for sequential effects. We applied linear mixed effects model analyses (R, version 3.4.2; Package: 'lme4'/'lmerTest'; R Core Team 2018) with explanatory variables Frame, Time, and Need; participants were included as random effects.

\subsection{Results}

We analyzed the data of all 19 participants, removing the catch trials. On average, they answered about 10 out of 192 catch trials incorrectly, i.e., correct average proportion was $94.6 \%$. Of the remaining 14,592 test trials, $103(0.7 \%)$ were timeouts and were also removed from further analysis. In all three induced need conditions $(0,2500$, and 3500 target points), the mean number of points obtained in the games was about the same $(2616,2678$, and 2656 points, respectively). In $62 \%$ of the trials, participants chose the gamble. Mean response times for gain frame trials and loss frame trials were about the same: $1.12 \mathrm{~s}(\mathrm{SD}=0.452)$ and $1.08 \mathrm{~s}$ $(\mathrm{SD}=0.464)$, respectively, under the $3-\mathrm{s}$ time limit condition and $0.63 \mathrm{~s}$ $(\mathrm{SD}=0.136)$ and $0.61 \mathrm{~s}(\mathrm{SD}=0.136)$, respectively, under the $1 \mathrm{~s}$ time limit condition. No further analysis of response times is pursued here.

Prior to the statistical model analysis, we tested for sequential effects (autocorrelation) in choice behavior. In particular, participants could be more/less risk taking as a function of points accumulated at trial $i, i=1, \ldots, 80$. Across all participants, the number of risky choices was counted for each trial $i$, separately for each experimental block. Because the auto-correlations (Pearson) between the first and second halves of trials showed no significant results (Table 9, Appendix 7); points earned at trial $i$ were not included as a covariate in the following analysis.

The linear mixed effects model analysis showed statistically significant main effects for Frame, Time, and Need (3500) (Table 1). Participants chose the risky 
Table 1 Experiment 1: linear mixed effects model fit by restricted maximum likelihood (REML)

\begin{tabular}{|c|c|c|c|c|c|c|c|c|}
\hline \multirow[t]{2}{*}{ Factor } & \multicolumn{4}{|l|}{ Model 1} & \multicolumn{4}{|l|}{ Model 2} \\
\hline & $\beta$ & SE & $t$ value & Sig. & $\beta$ & SE & $t$ value & Sig. \\
\hline Frame (gain) & -0.202 & 0.008 & -26.587 & $* * *$ & -0.281 & 0.015 & -18.487 & $* * *$ \\
\hline Time $(3 \mathrm{~s})$ & 0.042 & 0.008 & 5.502 & $* * *$ & -0.024 & 0.015 & -1.588 & \\
\hline Need (2500) & -0.007 & 0.009 & -0.703 & & -0.021 & 0.016 & -1.325 & \\
\hline Need (3500) & 0.046 & 0.009 & 4.932 & $* * *$ & 0.045 & 0.016 & 2.806 & $* * *$ \\
\hline Frame $\times$ Time & & & & & 0.134 & 0.015 & 8.818 & $* * *$ \\
\hline Frame $\times$ Need $(2500)$ & & & & & 0.023 & 0.019 & 1.227 & \\
\hline Frame $\times$ Need $(3500)$ & & & & & 0.011 & 0.019 & 0.594 & \\
\hline Time $\times$ Need $(2500)$ & & & & & 0.007 & 0.019 & 0.364 & \\
\hline Time $\times$ Need $(3500)$ & & & & & -0.010 & 0.019 & -0.526 & \\
\hline (Intercept) & 0.690 & 0.030 & 23.218 & $* * *$ & 0.729 & 0.031 & 23.584 & $* * *$ \\
\hline
\end{tabular}

Dependent variable: responses (risky option). Reference categories: Frame, Loss; Time Limit, 1 s; Need, 0 . Number of observations: 14,489, groups (random effects): subjects, 19. Significance codes: $* * * p<0.01, * * 0.05, * 0.1 . \beta$ : estimated coefficient

option significantly more often in the loss frame (72\%) than in the gain frame (52\%) suggesting a framing effect (reflection effect; Tversky and Kahneman 1981). Furthermore, participants chose the risky option significantly less often under shorter time limits (60\%) than under longer time limits (64\%). With respect to Need, the participants chose the risky option more often when Need was high (Need (3500): 66\%) as compared to the remaining need conditions (Need (0): 61\%; Need (2500): 60\%) (Table 1, Model 1, main effects).

To investigate possible moderator effects of time constraints and induced needs on choice frequencies under different frames, we performed a linear mixed effects model with a two-way interaction analysis. We found that Frame by Time interactions were statistically significant, but neither Frame by Need nor Need by Time interactions (Table 1, Model 2, interactions). Time constraints seem to reinforce the framing effect, i.e., the tendency to choose the gamble in loss frames and the sure option in gain frames. Under shorter time limits, participants tend to be even more risk averse when the lottery was framed as a gain (47\%) and more risk seeking when the lottery was framed as a loss $(74 \%)$ than under longer time limits (58\% in the gain frame as compared to $71 \%$ in the loss frame).

A framing effect may manifest itself in a preference reversal or in a preference shift (Tversky and Kahneman 1981; Kühberger 1998). Figure 3 shows the choice proportion for the 16 individual test games within each condition as a function of time limit conditions for the gain (Fig. 3a) and loss (Fig. 3b) frames and as a function of the frame conditions for time limit $3 \mathrm{~s}$ (Fig. 3c) and $1 \mathrm{~s}$ (Fig. 3d) for all three need conditions. Each choice proportion is based on 76 games (4 replications for each of the 19 participants). Choice proportions in the upper left and lower right quadrant indicate preference reversals; off-diagonal choice proportions in the upper right and lower left quadrant indicate preference shifts. There are some preference 
A

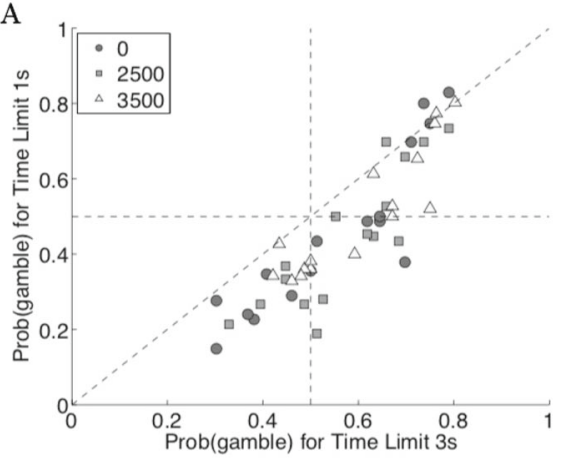

$\mathrm{C}$

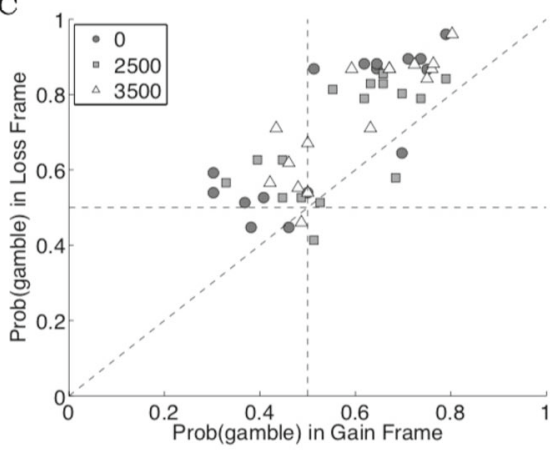



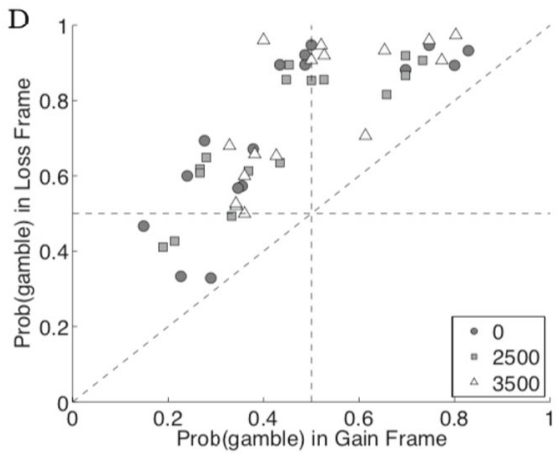

Fig. 3 Experiment 1: choice proportions for choosing the gambles as a function of time limits for a gain frame (a) and a loss frame (b) and as a function of frames with $3 \mathrm{~s}(\mathbf{c})$ and $1 \mathrm{~s}(\mathbf{d})$. The symbols and gray shades correspond to the need conditions with darker shades to lower points

reversals as a function of time limits in the gain frame condition (Fig. 3a); and very few in the loss frame condition (Fig. 3b). The pattern looks different when we consider the choice proportions as a function of frames given a time limit condition ( $3 \mathrm{~s}$ and $1 \mathrm{~s}$ are shown in Fig. 3c, d, respectively). A further analysis of the framing effect across all games, separate for each need and time limit condition, can be found in Appendix 2 (Table 4; Fig. 11).

The framing effect may also depend on the concrete values defining a gamble (Kühberger et al. 1999). Therefore, we plotted the choice proportions for choosing the gamble as a function of probabilities to keep the initial amounts (Fig. 4a, b) as well as a function of the initial amount given across the probabilities of keeping it (Fig. 4c, d), similar to the presentation in De Martino et al. (2006). The framing effect-gain vs loss frame-is clearly preserved in the need conditions (solid vs filled bars with different gray shades) as well across the time limits. The probability of choosing the gamble depends also on the probability of keeping. The smaller the keeping probability is the less often the gamble is chosen. This is in stark contrast to the results of De Martino et al. (2006), where the probability of choosing the gamble decreases with increasing keeping probabilities. We will return to this in the discussion. The probability of choosing the gamble also seems to depend on the 


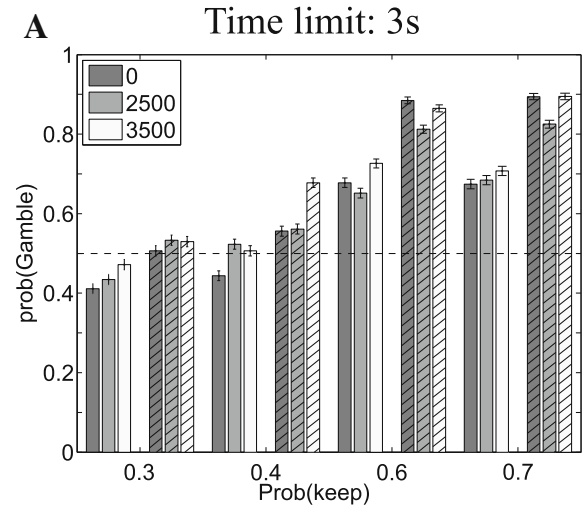

B

Time limit: $1 \mathrm{~s}$

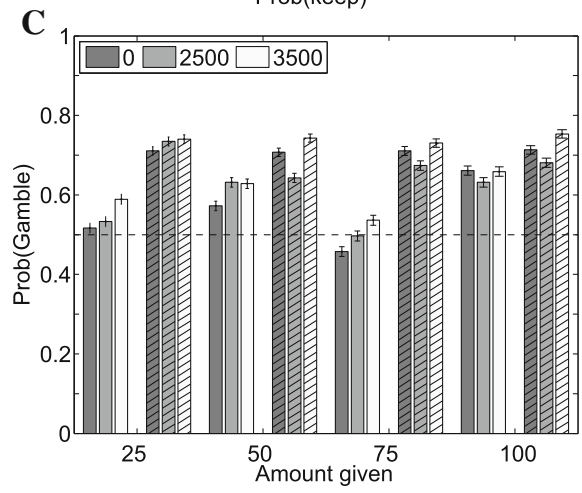

D


Fig. 4 Experiment 1: choice proportions for choosing the gambles as a function of the probability of keeping across all four initial amounts within the given probability $(\mathbf{a}, \mathbf{b})$ and as a function of the initial amount given across the probabilities of keeping it (c, d). The 3-s time limit condition is presented in $\mathbf{a}$ and $\mathbf{c}$; the 1-s condition in $\mathbf{b}$ and $\mathbf{d}$. The solid bars refer to the gain frame condition, the filled ones to the loss frame condition. The gray shades correspond to the need conditions with darker shades to lower points

initial amount given but not in a systematic way, that is, it is neither decreasing as a function of the amount given, as in the De Martino et al. (2006) study, nor increasing. Therefore, we investigated the results on the individual participant's level as well.

\subsection{Individual differences}

The self-assessment of risk attitudes varied between 1 and 4 (mean $=1.95$, median $=2$, and standard deviation $=0.9$ ). The willingness to take risk measured in terms of the sum of scores of the six items (Question 1 in Appendix 1) yielded between 7 and 20 points, with 0 being the lowest possible points to reach (no willingness to take risk) and 30 the highest possible scores to obtain (willingness for taking high risk) $($ mean $=11$, median $=10$, std $=3.4)$. For the willingness to bet in a risky gamble scores ranged between 0 and 3 (mean $=1$, median $=1$, std $=0.85$ ). Detailed results are in Appendix 3 (Table 5). The correlation between 
the overall scores of the willingness-to-take-risk scales plus the willingness-to-bet scales and the self-assessment scores was 0.59 .

The overall scores served to divide the participants into two groups, labeled $R_{\text {high }}$ and $\mathrm{R}_{\text {low }}$, with the median as criterion. $\mathrm{R}_{\text {high }}$ is the riskier group. In addition, we performed a hierarchical cluster analysis (complete and average) on the choice proportions for the four game replications of all participants across all experimental conditions.

Two major clusters were identified with seven and ten participants each, in the following labeled as $G_{\text {high }}$ and $G_{\text {low }}$. A third small cluster, G3, contained two participants. Both clustering methods gave the same results. A k-means cluster analysis with $k=2$ suggested to merge $\mathrm{G}_{\text {high }}$ and G3. Results shown are based on the 2-means clustering. Participants in $\mathrm{G}_{\text {high }}$ chose the gamble in $71.2 \%$ of all cases whereas participants in $\mathrm{G}_{\text {low }}$, chose it in $54.3 \%$ of all cases. The overlap between the two risk attitude groups and the clusters is moderate with five common members in $\mathrm{R}_{\text {high }}$ and $\mathrm{G}_{\text {high }}$ and six common members in $\mathrm{R}_{\text {low }}$ and $\mathrm{G}_{\text {low }}$. Analysis was done with both classification results; however, only the one based on the statistical clustering is reported here because it gave more differentiating results.

On average, participants of $\mathrm{G}_{\text {high }}$ answered 15 out of 192 catch trials incorrectly, i.e., correct average proportion was $92.4 \%$ whereas those of $\mathrm{G}_{\text {low }}$ answered about 6 out of 192 catch trials incorrectly, i.e., correct average proportion was $96.7 \%$. A t-test showed that the difference between the proportion of incorrect catch trials of both groups was statistically significant $(t=2.230, d f=17, p<0.05)$. In all three induced need conditions ( 0,2500 and 3500 target points), the mean number of points obtained in the games was $2562.85,2674.17$ and 2632.22 points for $\mathrm{G}_{\mathrm{high}}$, respectively, and 2664.69, 2681.56 and 2678.06 points for $G_{\text {low }}$, respectively. Furthermore, the mean response time of participants in $\mathrm{G}_{\text {low }}$ was shorter $(0.87 \mathrm{~s})$ than the one for participants in $\mathrm{G}_{\text {high }}(0.90 \mathrm{~s})(t=4.591, d f=14487, p<0.01)$. Further analysis of the RT is here omitted.

The linear mixed-effects model analysis conducted separately for each group revealed significant main effects for Frame and Time in both groups, and also Need (3500) in $\mathrm{G}_{\text {high }}$ (see Table 6, Appendix 4). A subsequent two-way interaction analysis showed statistically significant results for Frame by Time for both groups. Furthermore, for $\mathrm{G}_{\text {high }}$, there was a significant effect for Need (3500) by Time. As before the interaction of Frame by Time indicates an increased framing effect when time is short $\left(\mathrm{G}_{\mathrm{high}}: 55 \%\right.$ and $83 \%$ in the gain and loss frame, respectively, for the 1s time limit condition as compared to $67 \%$ and $81 \%$ in the gain and loss frame, respectively, for the 3 -s time limit condition; $\mathrm{G}_{\mathrm{low}}: 40 \%$ and $66 \%$ in the gain and loss frame, respectively, for the 1-s time limit condition as compared to $49 \%$ and $63 \%$ in the gain and loss frame, respectively, for the 3 -s time limit condition). In addition, for $\mathrm{G}_{\text {high }}$, the differences in risky choices between short and long time constraints tend to decrease with increasing level of Need. That is, for $\mathrm{G}_{\text {high }}$ induced need tends to reduce the effect of time pressure on choice behavior (Need (0): $1 \mathrm{~s}$, 66\% and 3 s, 74\%; Need (2500): 66\% and 72\%; (Need 3500): 73\% and 76\%).

Figure 5 shows a scatter plot of response proportions for choosing the gamble as a function of time limits (Fig. 5a-d) given a frame and as a function of frames given 

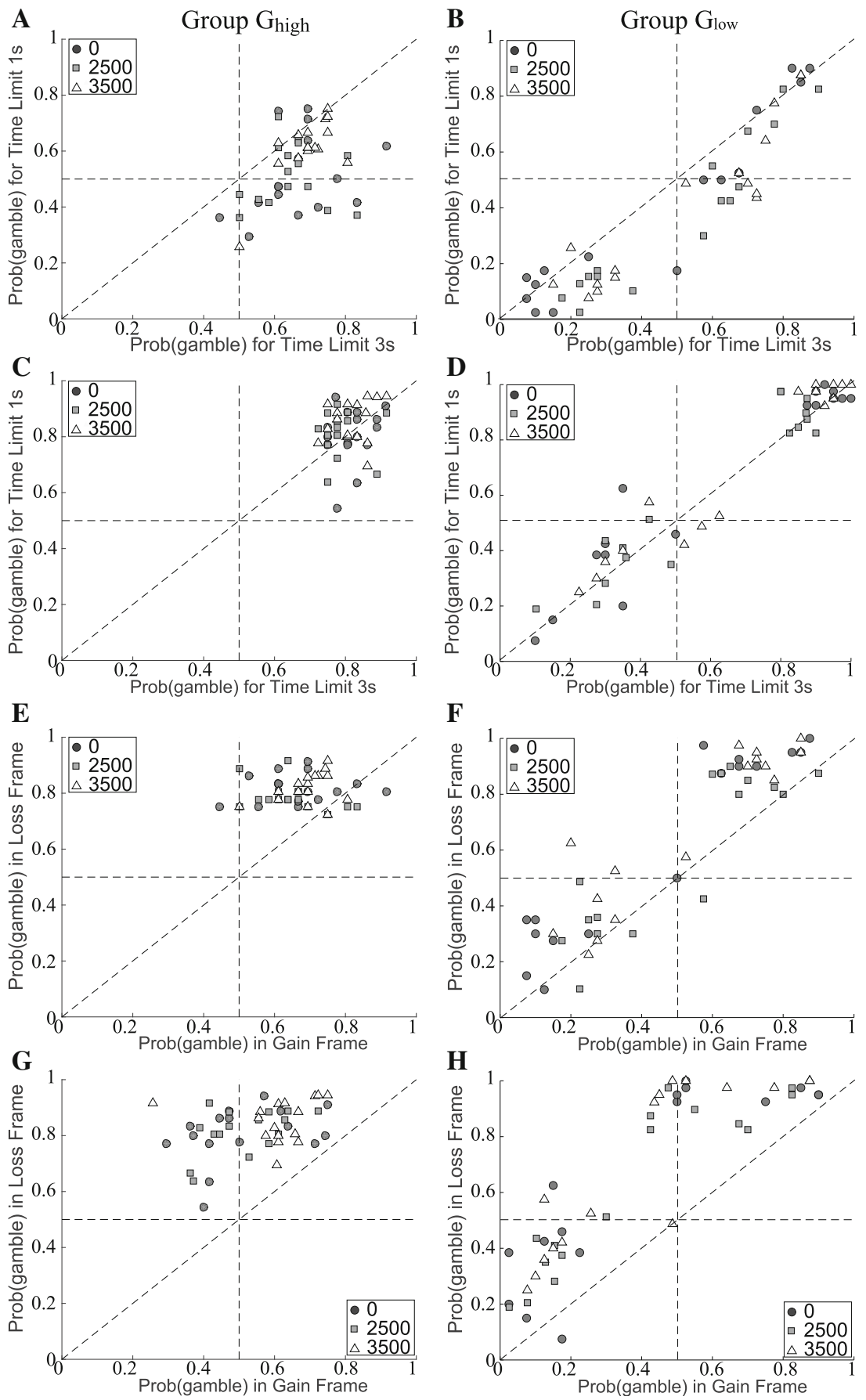
4Fig. 5 Experiment 1: choice proportions for choosing the gambles as a function of time limits for a gain frame $(\mathbf{a}, \mathbf{b})$ and a loss frame $(\mathbf{c}, \mathbf{d})$ and as a function of frames with $3 \mathrm{~s}(\mathbf{e}, \mathbf{f})$ and $1 \mathrm{~s}(\mathbf{g}, \mathbf{h})$ separated by groups. The left panels refer to $\mathrm{G}_{\text {high }}$ and the right panels to $\mathrm{G}_{\text {low }}$. The symbols and gray shades correspond to the need conditions with darker shades to lower points

a time limit separated by groups $\left(\mathrm{G}_{\text {high }}\right.$, left; $\mathrm{G}_{\text {low }}$ right). For $\mathrm{G}_{\text {high }}$, each choice proportion is based on 28 trials (4 replications for each of the 7 participants), and for $\mathrm{G}_{\text {low }}$ on 40 trials. Obviously, $\mathrm{G}_{\text {high }}$ is more risk taking than $\mathrm{G}_{\text {low }}$ as the choice proportions are mainly in the upper two quadrants. A detailed analysis of framing effects and preference reversals for each group and treatment is found in Table 4 and Fig. 11 in Appendix 2. Note that the framing effects include preference reversals and preference shifts. Preference reversals occur more often for $\mathrm{G}_{\text {high }}$ $(n=7)$ (Fig. 5, upper left and lower right quadrants; Table 4, Appendix 2) than for $\mathrm{G}_{\text {low }}(n=10)$. Furthermore, most preference reversals for $\mathrm{G}_{\text {high }}$ occur in the Need (0) condition; in $\mathrm{G}_{\text {low }}$ most preference reversals in the Need (3500) condition.

We also investigated the framing effect on the level of gambles separately for each group. That is, we plotted the choice proportions for choosing the gamble as a function of probabilities to keep the initial amounts (Fig. 6a-d) as well as a function of the initial amount given across the probabilities to keep it (Fig. 6e-h). The results of $G_{\text {high }}$ are shown in the left panels and the results of $G_{\text {low }}$ in the right panels. The framing effect is preserved across frames (solid vs filled) and time limits (Fig. 6a vs Fig. $6 c$ for $\mathrm{G}_{\text {high }}$; Fig. 6 b vs Fig. $6 \mathrm{~d}$ for $\mathrm{G}_{\text {low }}$ ) for each need condition. Considering the 75 amount given in panels $\mathrm{e}-\mathrm{h}$ in the gain frame it still sticks out, causing a nonmonotonicity in choice proportions as a function of amounts given.

\subsection{Summary and discussion}

The overall results corroborate those by De Martino et al. (2006), i.e., gain and loss framing changes the response behavior of the participant. In a gain frame, the participant chooses the sure option more often than in a loss frame. Furthermore, the study replicates the results by Guo et al. (2015); Guo et al. (2017), i.e., time limits enhance the framing effect. Under short time limits, the participant tends to choose the sure option much more often in the gain frame as compared to the loss frame. Induced need, i.e., a target amount a participant has to be reached by his/her action also has an effect on choice behavior. Under a high level of induced need, participants tend to choose the risky option more often as compared to the no need or medium need condition. However, no moderating effect of induced need on framing effects could be observed, which contradicts our working hypothesis.

Individual differences in risk attitudes may also contribute to the size of the framing effect. Therefore, several measures were taken to access a person's risk attitude. Furthermore, a cluster analysis based on choice behavior was conducted, resulting in two groups. The relation between stated risk attitudes (self-assessment tests) and revealed risk attitudes (frequency of choosing the gamble) was moderate. For both groups, we could observe framing effects and time constraints reinforcing them. Furthermore, Need had also a very similar effect compared to the result of the 


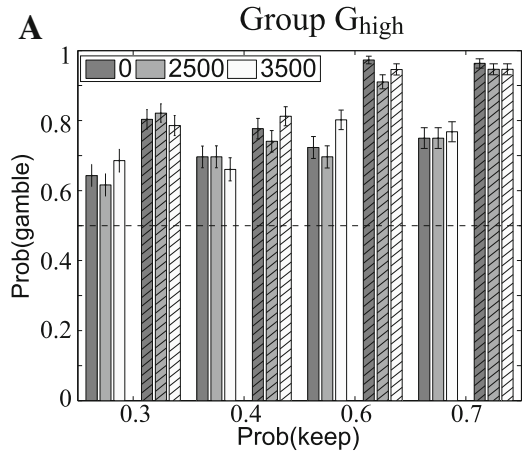

C
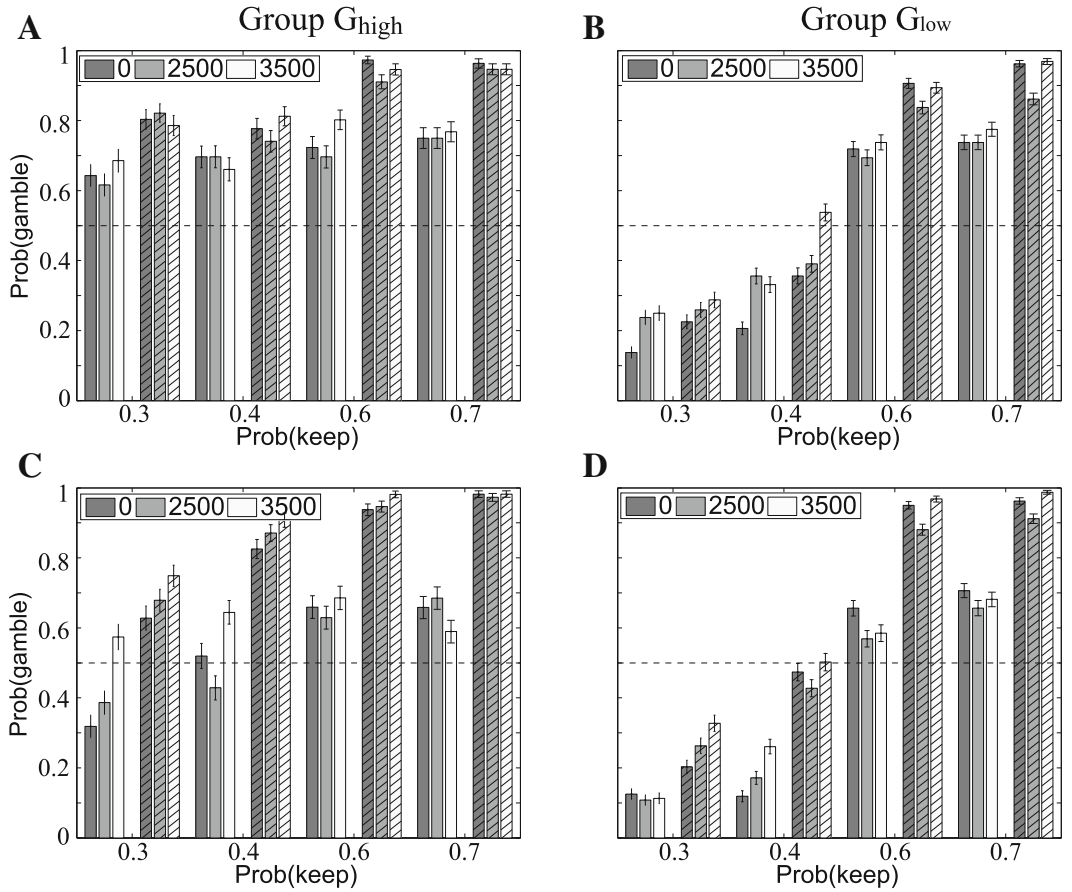

D
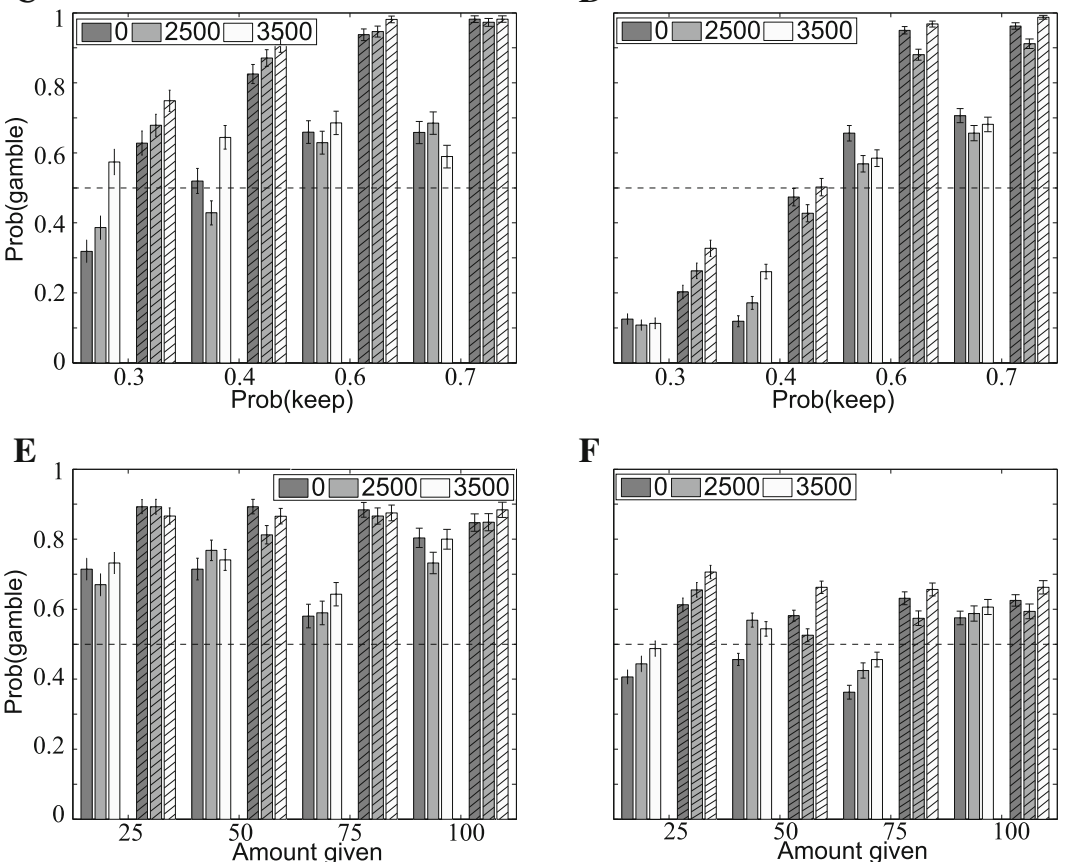

F
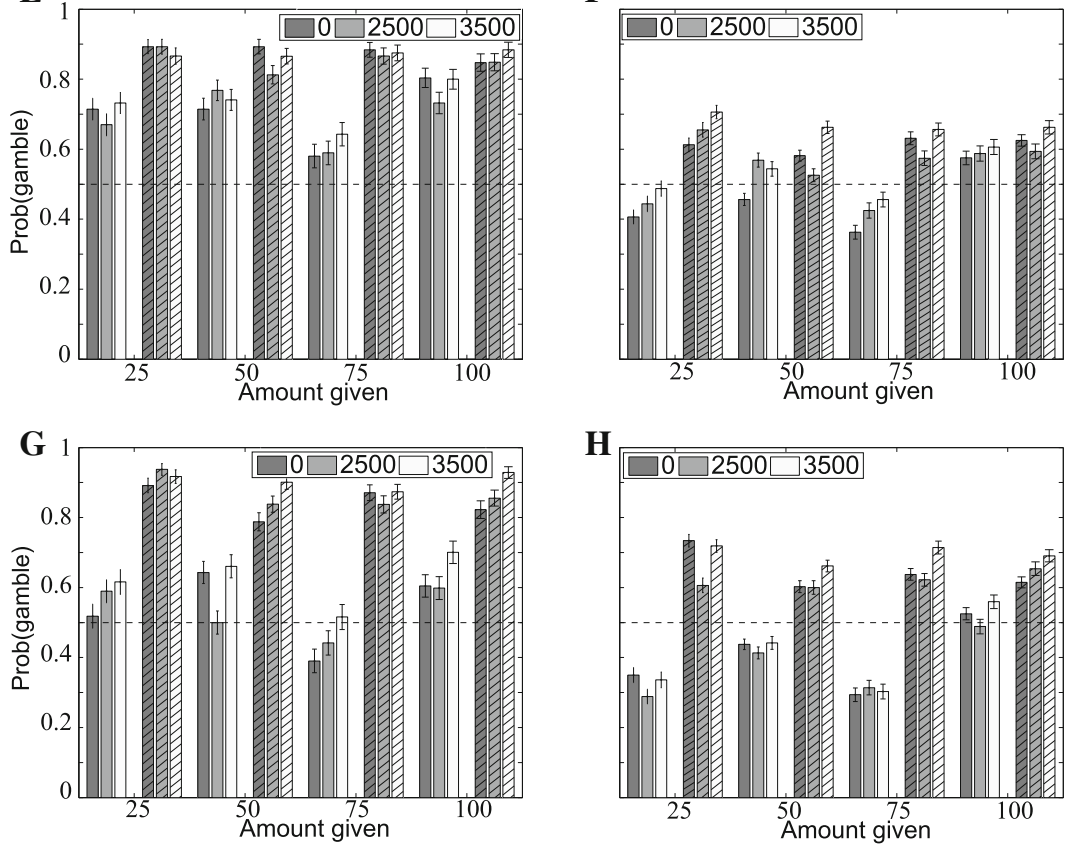
4Fig. 6 Experiment 1: choice proportions for choosing the gambles as a function of the probability of keeping across all four initial amounts within the given probability (a-d) and as a function of the initial amount given across the probabilities of keeping it $(\mathbf{e}-\mathbf{h})$. The results of $\mathrm{G}_{\text {hih }}$ are shown in the left panels and those of $\mathrm{G}_{\text {low }}$ in the right panels. The 3-s time limit condition is presented in $\mathbf{a}$ and $\mathbf{b}$ and in $\mathbf{e}$ and $\mathbf{f}$; the 1-s condition is presented in $\mathbf{c}$ and $\mathbf{d}$ and in $\mathbf{g}$ and $\mathbf{h}$. The solid bars refer to the gain frame condition, the filled ones to the loss frame condition. The gray shades correspond to the need conditions with darker shades to lower points

entire sample. Interestingly, Need can also be a moderator on the effect of time pressure. This was different for both groups.

The choice proportions in the gain frame for the 75 initial amount conditions are smaller than for the 50 initial amount and for the 100 initial amount conditions. This applies for the entire sample and for both groups. Excluding any technical errors, we speculated that the displayed amount in the sure option may have caused some effect (different from multiples of 5, decimals were rounded to the next integer; e.g., Albers 2001; Bateman et al. 2007) but this is also true for the 25 initial amount condition. Furthermore, this is also valid for the loss frame where the 75 initial amount condition does not stick out. In any case, the amounts displayed may have had an effect, which we cannot explain. Finally, the choice proportions for choosing the gamble are increasing as a function of probabilities for keeping the amount, i.e., in opposite directions of the study by De Martino et al. (2006) and opposite to the predictions of prospect theory (Kahneman and Tversky 1979). To shed some light on some of the unexpected results we conducted a second experiment.

\section{Experiment 2}

The general setup of the second experiment is identical to the first one but with different initial amounts, Need levels, and procedure. The sample size is increase to further investigating individual differences in choice behavior. The statistical methods are the same as before.

\subsection{Participants}

Fifty-eight undergraduate students from Jacobs University Bremen and University of Bremen (29 female, age between 18 and 49 years, median: 20) were recruited as voluntary participants. They received a show-up fee of $9.00 €$ plus $0.0025 €$ per point earned in one of the six experimental blocks. The payment block was selected randomly. The experiment has been approved by the BIGSSS ethics committee. Participants gave their written informed consent prior to their inclusion in the study. They were screened for their ability to follow the experimental instructions and completed one session which lasted approximately $90 \mathrm{~min}$.

\subsection{Materials}

The experiment consisted of one session with six blocks of trials. One block of trials included 96 test trials: 48 gain frames and 48 loss frames. In addition, 8 catch trials 
were included in each block of trials, resulting in a total of 104 trials per block. For the test trials, 4 basic initial point amounts were selected: 20, 40, 60, and 80, flanked by plus/minus one point amounts, resulting in the following set: 19, 20, 21, 39, 40, $41,59,60,61,79,80$, and 81 . This was done to minimize the effect of prominent numbers on choice behavior. Responses to a triple were collapsed for evaluation. The probabilities of winning the gamble were identical to Experiment 1: 0.3, 0.4, 0.6 and 0.7. The initial amounts and probabilities were paired to form 48 unique games. The time limits were the same as in Experiment 1: $1 \mathrm{~s}$ and $3 \mathrm{~s}$. Need levels were 0,2800 , and 3600 points. 52 games (48 test and 4 catch trials) for each of the 2 frames and each of the 2 response time limits and each of the 3 Need levels result in a grand total of 624 observations per participant.

\subsection{Apparatus}

The control software was identical to the one in Experiment 1. In addition to the Linux system, five other computers running Microsoft operating system (Windows 7) were used. Two of them had a smaller standard $17^{\prime \prime}$ LCD monitor (screen resolution: $1280 \times 960$ pixels). The input devices were standard keyboards with the left and right arrow keys to choose the choice option displayed left or right on the screen, respectively.

\subsection{Procedure}

The participants performed one session. The instructions and training trials were similar to the one in Experiment 1. The first two experimental blocks were a 0-Need condition with a 3-s time limit condition in the first block and a 1-s time limit condition in the second block for all participants. They served as a benchmark. The remaining need and time limit conditions were pseudo-randomized but with the same need condition in two consecutive blocks. After each block, the participants had a break. They could continue when they were ready for the next block.

\subsection{Results}

Data of one participant were lost due to a computer failure. Data of three participants were excluded from the analysis for the following reasons: for two participants the proportion of incorrect catch trials was above 50\% and one participant did not respond within the time limits. Of the remaining 54 participants, the correct average proportion was $76.5 \%$. Of the remaining 33696 test trials, 291 trials were timeouts or anticipations $(<300 \mathrm{~ms})$ and were removed from the analysis. In all three need conditions $(0,2800,3600)$, the mean number of points was about the same $(2598,2628$, and 2617 points, respectively). In $61 \%$ of all trials, participants chose the gamble. Mean response times for gain frame trials were $1.24 \mathrm{~s}(0.65 \mathrm{~s})$ as compared to $1.24 \mathrm{~s}(0.64 \mathrm{~s})$ in loss framed trails. No further analysis on response times is pursued here. Data are analyzed in the same way as in Experiment 1. 
Table 2 Experiment 2: linear mixed effects model fit by restricted maximum likelihood (REML)

\begin{tabular}{|c|c|c|c|c|c|c|c|c|}
\hline \multirow[t]{2}{*}{ Factor } & \multicolumn{4}{|l|}{ Model 1} & \multicolumn{4}{|l|}{ Model 2} \\
\hline & $\beta$ & SE & $t$ value & Sig. & $\beta$ & SE & $t$ value & Sig. \\
\hline Frame (gain) & -0.186 & 0.005 & -35.054 & $* * *$ & -0.258 & 0.011 & -24.323 & $* * *$ \\
\hline Time (3s) & 0.006 & 0.005 & 1.207 & & -0.014 & 0.011 & -1.308 & \\
\hline Need (2800) & 0.004 & 0.006 & 0.589 & & -0.015 & 0.011 & -1.321 & \\
\hline Need (3600) & 0.020 & 0.007 & 3.075 & $* * *$ & 0.006 & 0.011 & 0.511 & \\
\hline Frame $\times$ Time & & & & & 0.070 & 0.011 & 6.601 & $* * *$ \\
\hline Frame $\times$ Need $(2800)$ & & & & & 0.062 & 0.013 & 4.769 & $* * *$ \\
\hline Frame $\times$ Need $(3600)$ & & & & & 0.049 & 0.013 & 3.751 & $* * *$ \\
\hline Time $\times$ Need $(2800)$ & & & & & -0.024 & 0.013 & -1.871 & \\
\hline Time $\times$ Need $(3600)$ & & & & & -0.020 & 0.013 & -1.563 & \\
\hline (Intercept) & 0.693 & 0.018 & 39.517 & $* * *$ & 0.721 & 0.019 & 38.973 & $* * *$ \\
\hline
\end{tabular}

Dependent variable: responses (risky option). Reference categories: Frame, Loss; Time Limit, 1 s; Need, 0 . Number of observations: 30,489, groups (random effects): subjects, 54. Significance codes: $* * * p<0.01, * * 0.05, * 0.1 . \beta$ : estimated coefficient

As for Experiment 1, the auto-correlation (Pearson) between the first and second halves of trials showed no significant results (Table 10, Appendix 7) and, therefore, points earned at trial $i$ were not included as a covariate in the following analysis. Different from the results of Experiment 1, the linear mixed-effects model analysis showed a statistically significant main effect only for Frame and Need, but not for Time (Table 2). Participants chose the risky option significantly more often in the loss frame $(70 \%)$ than in the gain frame (52\%), suggesting a framing effect (reflection effect). For high induced need, participants tend to choose the risky option more often (Need (3600): 62.7\%) as compared to the other need conditions (Need (0): 60.3\%; Need (2800): 60.8\%)

A two-way interaction model showed statistically significant moderating effects of Time and Need (2800 and 3600) on framing effects. In particular, for the 3-s (1 s) time limit condition, the proportion of choosing the gamble was 54\% (50\%) and $69 \%(72 \%)$ for the gain and loss frame trials, indicating an increased framing effect under shorter time limits. For condition Need (0), the proportion for choosing the risky options was $49 \%$ for the gain frame and $71 \%$ for the loss frame; for condition Need (2800), the respective proportions were 53\% and 69\%, and for condition Need (3600) $54 \%$ and $71 \%$. That is, Need seems to increase the number of risky choices in the gain frame. Note that for condition Need (0), we observed a preference reversal; for the remaining conditions, we observed a preference shift.

Figure 7 shows the choice proportion for the 16 individual test games within each condition as a function of time limit conditions for the gain (Fig. 7a) and loss (Fig. 7b) frame and as a function of the frame conditions for time limit $3 \mathrm{~s} \mathrm{(Fig.} \mathrm{7c)}$ and $1 \mathrm{~s}$ (Fig. 7d) for all three need conditions. Each choice proportion is based on 162 games ( 3 quasi-replications for each of the 54 participants). Choice proportions in the upper left and lower right quadrant indicate preference reversals; off-diagonal choice proportions in the upper right and lower left quadrants indicate preference 
A
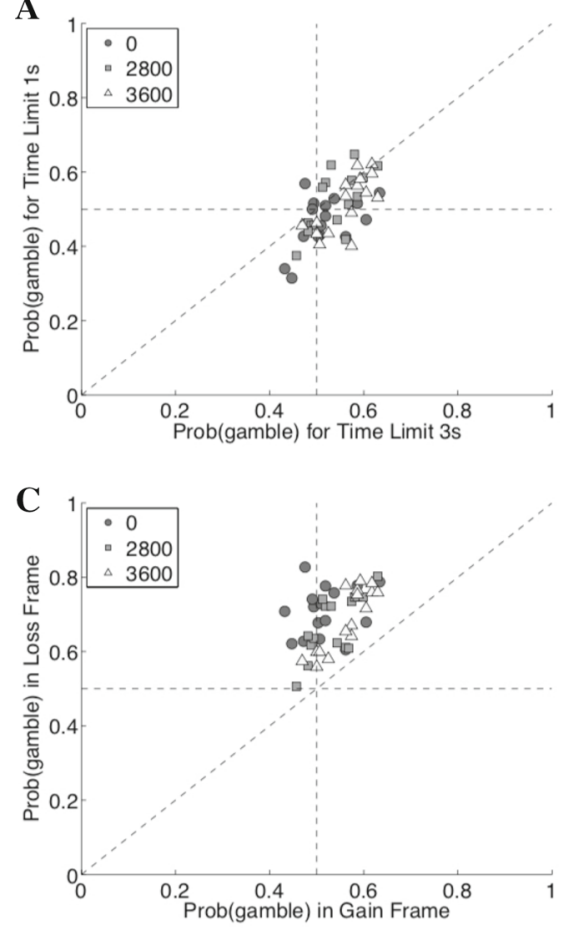

B

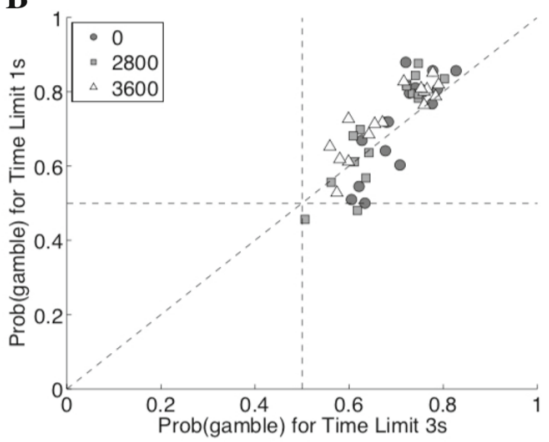

D

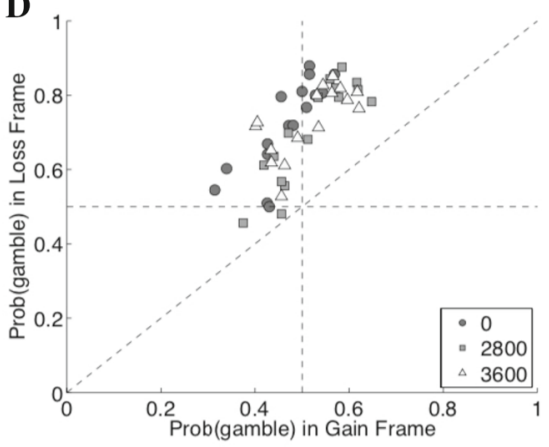

Fig. 7 Experiment 2: choice proportions for choosing the gambles as a function of time limits for a gain frame (a) and a loss frame (b) and as a function of frames with $3 \mathrm{~s} \mathrm{(c)} \mathrm{and} 1 \mathrm{~s}(\mathbf{d})$. The symbols and gray shades correspond to the need conditions with darker shades to lower points

shifts. There are some preference reversals as a function of time limits in the gain frame condition (A); and almost none in the loss frame condition (B). For the choice proportions as a function of frames given a time limit condition ( $3 \mathrm{~s}$ and $1 \mathrm{~s}$ are shown in Fig. 7c and d, respectively), we observe substantial more preference reversals and preference shifts. A further analysis of the framing effect across all games, separate for each need and time limit condition, can be found in Appendix 5 (Table 8; Fig. 12).

Figure 8 shows the choice proportions for choosing the gamble as a function of probabilities to keep the initial amounts (Fig. 8a, b) as well as a function of the initial amount given across the probabilities of keeping it (Fig. 8c, d). Again, the framing effect-gain vs loss frame-is clearly preserved in the need conditions (solid vs filled bars with different gray shades) as well across the time limits. The probability of choosing the gamble depends to some extent on the probability of keeping, more pronounced under short time limits (Fig. 8b). The smaller the keeping probability is the less often the gamble is chosen, as could be observed for Experiment 1 . The probability of choosing the gamble seems to depend less on the initial given amount (Fig. 8c, d). As before, we investigated the results on the individual participant's level groups according to some characteristics as well. 
A
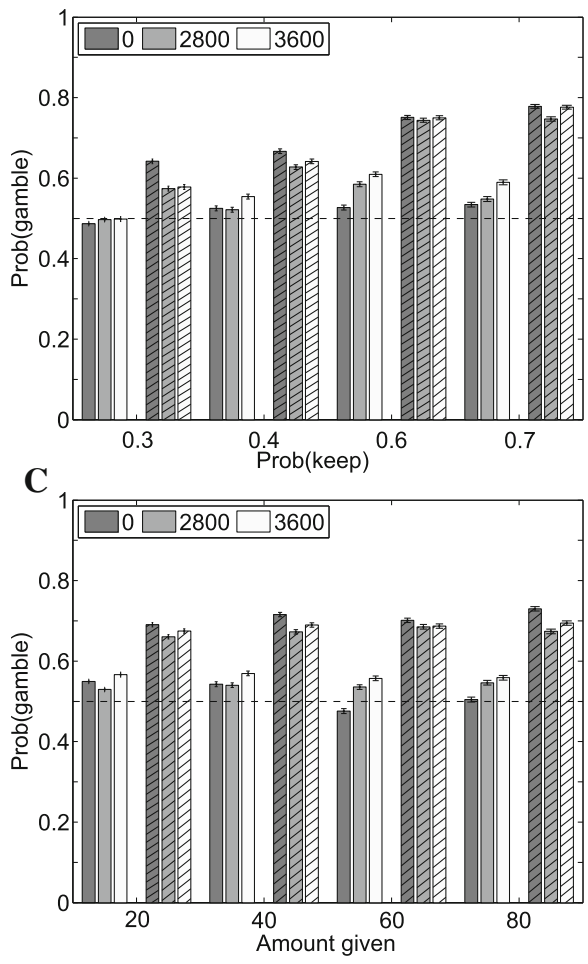

B

Time limit: $1 \mathrm{~s}$

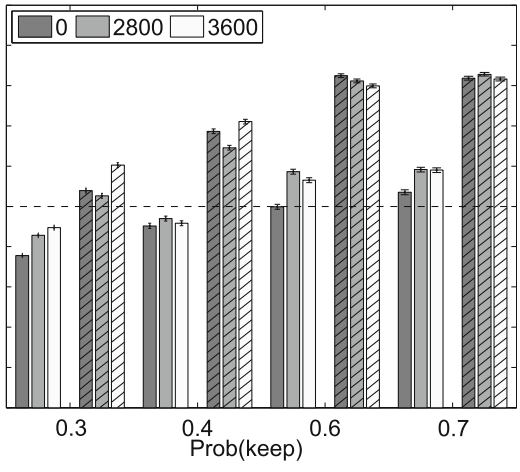

D

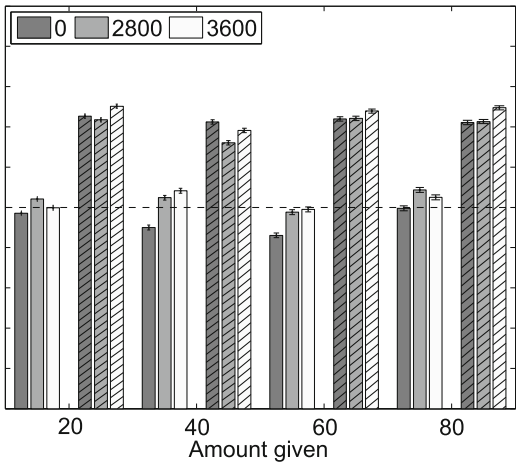

Fig. 8 Experiment 2: choice proportions for choosing the gambles as a function of the probability of keeping the amount across all four initial amounts within the given probability (a, b) and as a function of the initial amount given across the probabilities of keeping it (c, d). The 3-s time limit condition is presented in the left panels; the 1-s condition in the right panels. The solid bars refer to the gain frame condition, the filled ones to the loss frame condition. The gray shades correspond to the need conditions with darker shades to lower points

\subsubsection{Individual differences}

Of the 54 participants, 49 completed the risk-assessment test. The self-assessment of risk attitudes varied between 0 and 4 (mean $=2.6$, median $=3$, standard deviation $=1.1$ ). The willingness to take risk measured in terms of the sum of scores of six items yielded between 6 and 25 points $($ mean $=14.1$, median $=13$,

Table 3 Experiment 2: demographic information and results of the self-assessment scores including the correlation between scores of subtests

\begin{tabular}{|c|c|c|c|c|c|c|c|c|}
\hline \multirow[t]{2}{*}{ Group } & \multirow{2}{*}{ Mean age } & \multirow[t]{2}{*}{ Sex } & \multicolumn{3}{|c|}{ Mean score (std error) } & \multicolumn{3}{|c|}{ Correlation between } \\
\hline & & & Life (Li) & $\begin{array}{l}\text { Lottery } \\
\text { (Lo) }\end{array}$ & Self (S) & $\mathrm{Li}-\mathrm{Lo}$ & $\mathrm{Li}-\mathrm{S}$ & Lo-S \\
\hline $\mathrm{G} 1(n=30)$ & 20.3 & $17 \mathrm{f} / 13 \mathrm{~m}$ & $13.73(0.87)$ & $1.60(0.30)$ & $2.53(0.20)$ & 0.26 & 0.70 & 0.56 \\
\hline $\mathrm{G} 2(n=19)$ & 21.3 & $7 \mathrm{f} / 12 \mathrm{~m}$ & $14.79(1.18)$ & $2.05(0.34)$ & $2.79(0.23)$ & -0.26 & 0.51 & 0.08 \\
\hline
\end{tabular}


A
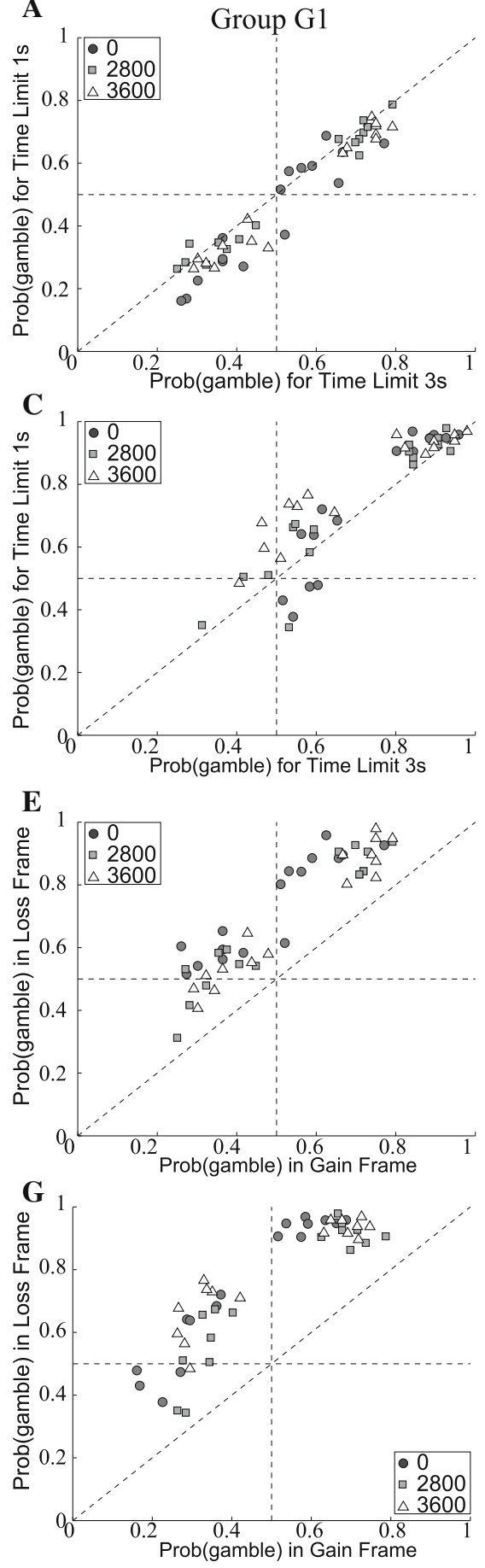

B
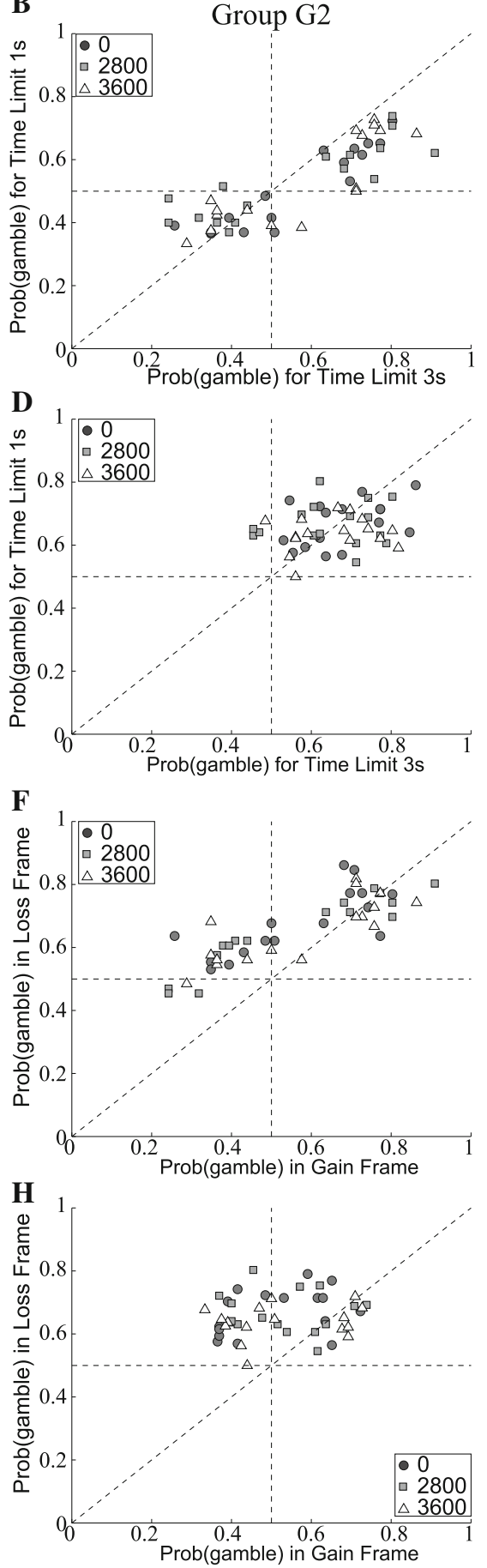
4 Fig. 9 Experiment 2: choice proportions for choosing the gambles as a function of time limits for a gain frame $(\mathbf{a}, \mathbf{b})$ and a loss frame $(\mathbf{c}, \mathbf{d})$ and as a function of frames with $3 \mathrm{~s}(\mathbf{e}, \mathbf{f})$ and $1 \mathrm{~s}(\mathbf{g}, \mathbf{h})$ separated by groups. The left panels refer to G1 and the right panels to G2. The symbols and gray shades correspond to the need conditions with darker shades to lower induced need

standard deviation $=4.9)$. For the willingness to bet in a risky gamble, values ranged between 0 and 5 (mean $=1.8$, median $=2$, standard deviation $=1.6$ ). Frequency distributions and further details are found in Appendix 6. Similar to Experiment 1, we performed a hierarchical cluster analysis (complete and average) on the choice proportions for the triple games (initial amounts differ by 1 or 2 points) of all 54 participants across all experimental conditions. Two clusters were identified with 32 and 22 participants each, in the following labeled as G1 and G2. Both clustering methods gave the same results. Furthermore, a k-means cluster analysis with $k=2$ gave the same results. Self-classification scores and clusters did not agree. There were only 26 out of 49 possible matches. Various scores (subtests and overall) were taken to classify the participants. However, none of these measures could differentiate response behavior in an obvious fashion (see also Table 3). Analysis based on the clustering is reported here.

On average, G1 answered about 10 out of 48 catch trials incorrectly (correct average proportion $79.7 \%$ ) whereas G2 answered about 14 out of 48 catch trials incorrectly (correct average proportion $71.8 \%$; difference between proportions is statistically significant: $t=-2.621 ; p<0.05)$.

In all three induced need conditions $(0,2800$, and 3600 target points), the mean number of points obtained in the games was about the same across conditions and groups (2586.10, 2651.64 and 2632.77 points for G1, respectively; 2608.79, 2578.25 and 2607.91 points for G2, respectively). In contrast to Experiment 1, participants in each cluster did not differ with respect to risk taking behavior. Here, participants in G1 chose the gamble in $61.9 \%$ of the cases, similar to participants in G2, who did so in $60.3 \%$ of the cases. Furthermore, participants in G1 were, on average, faster $(0.88 \mathrm{~s})$ than those in $\mathrm{G} 2(1.03 \mathrm{~s} ; t=-25.040, p<0.01)$. No further analysis on RT is pursued here.

A linear mixed-effects model analysis revealed statistically significant main effects for G1 for Frame and Need but not for Time whereas for G2, it revealed a statistically significant main effect for Frame and Time but not for Need (Table 7, Appendix 4). Participants of both groups chose the gamble more often in the loss frame than in the gain frame condition, with the effect being more pronounced for G1 (G1: 73\% vs 50\%; G2: 66\% vs 54\%). Furthermore, participants in G1 chose the gamble more often in the high-Need (3600) condition as compared to the no-Need (0) condition (64\% and $60 \%$, respectively). Participants in G2 chose the gamble more often in the 3-s time limit condition as compared to the 1-s time limit condition (61\% and $59 \%$, respectively).

A subsequent interaction analysis showed statistically significant results for Frame by Time, Frame by Need and Need by Time for G1. As before, we found a stronger framing effect with shorter time limits $(48 \%$ and $76 \%$ for the gain and loss frame, respectively, for the 1-s time limit condition as compared to $52 \%$ and $71 \%$ for the gain and loss frame, respectively, for the 3-s time limit condition). With 

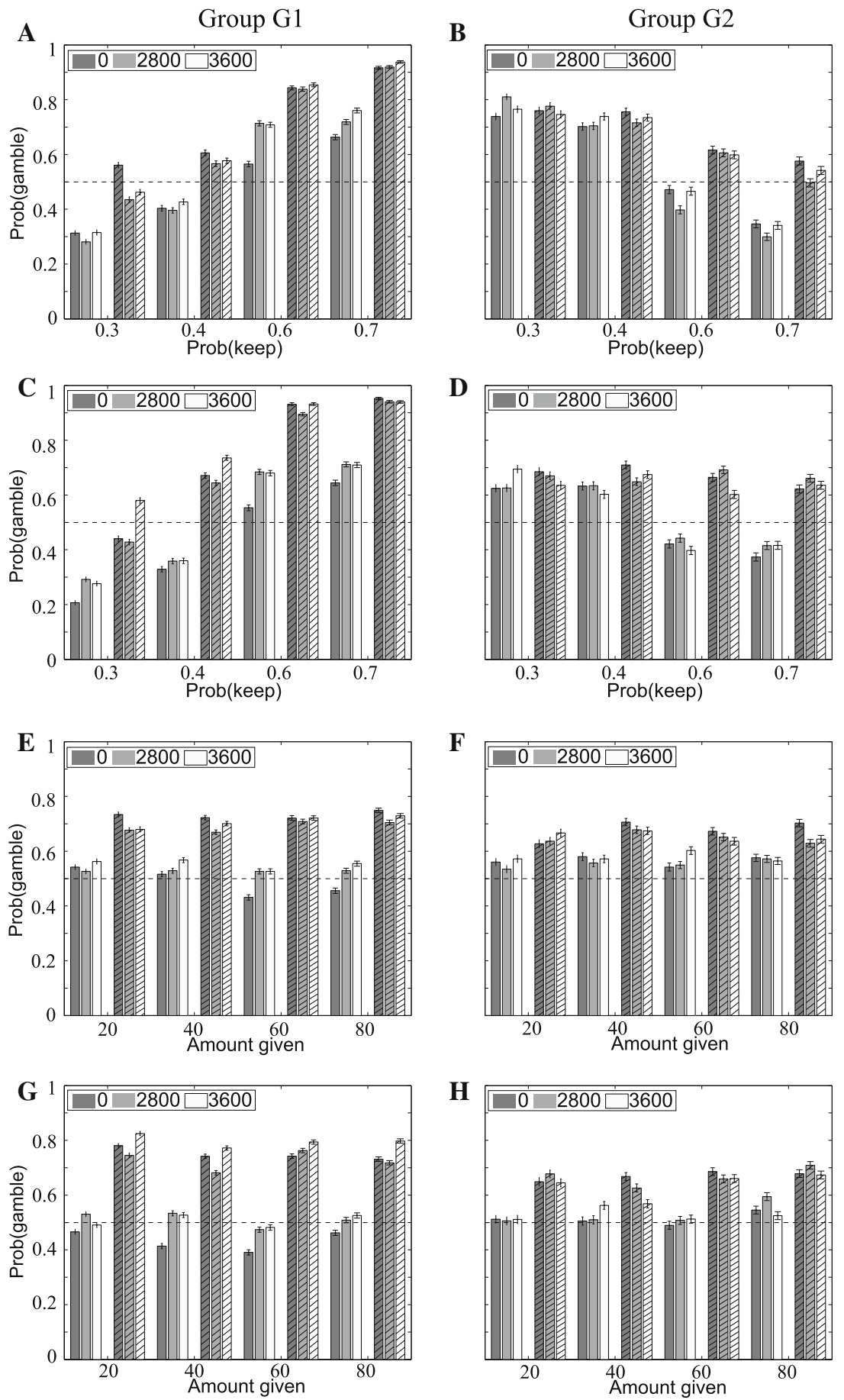
4Fig. 10 Experiment 2: choice proportions for choosing the gambles as a function of the probability of keeping across all four initial amounts within the given probability (a-d) and as a function of the initial amount given across the probabilities of keeping it (e-h). The results of G1 are shown in the left panels and those of G2 in the right panels. The 3-s time limit condition is presented in $\mathbf{a}$ and $\mathbf{b}$ and in $\mathbf{e}$ and $\mathbf{f}$; the 1-s condition is presented in $\mathbf{c}$ and $\mathbf{d}$ and in $\mathbf{g}$ and $\mathbf{h}$. The solid bars refer to the gain frame condition, the filled ones to the loss frame condition. The gray shades correspond to the need conditions with darker shades to lower points

respect to Need, there are stronger framing effects in Need (0) (46\% and 74\% for the gain and loss frame, respectively) as compared to the remaining need conditions (Need (2800): 52\% and 71\% for the gain and loss frame, respectively; Need (3600): $53 \%$ and $75 \%$, respectively). Moreover, Need seems to reverse the effect of different time limits (Need (0): 59\% and 61\% for $1 \mathrm{~s}$ and $3 \mathrm{~s}$, respectively; Need (2800): $62 \%$ and $61 \%$ for $1 \mathrm{~s}$ and $3 \mathrm{~s}$, respectively; Need (3600): $65 \%$ and $63 \%$ for $1 \mathrm{~s}$ and $3 \mathrm{~s}$, respectively). For G2, the analysis revealed statistically significant interaction effects for Frame by Time but not for Frame by Need and Need by Time. In sum, the observed effects and interactions tend to be stronger for G1 than for G2 (Table 7, in Appendix 4).

Figure 9 shows the choice proportion for 16 games within each need condition as a function of time limit conditions for the gain (Fig. 9a, b) and loss (Fig. 9c, d) frames and as a function of the frame conditions for time limit $3 \mathrm{~s} \mathrm{(Fig.} \mathrm{9e,} \mathrm{f)} \mathrm{and}$ $1 \mathrm{~s}$ (Fig. 9g, h) for all three need conditions. The left column presents the results for G1 ( $n=32$ participants), and the right column the results for G2 $(n=22$ participants). For G1 each choice proportion is based on 96 games (3 replications for each of the 32 participants), and for G2 on 66 games. Choice proportions in the upper left and lower right quadrants indicate preference reversals; off diagonal choice proportions in the upper right and lower left quadrants indicate preference shifts. Some preference reversals as a function of time limits occur in the loss frame (Fig. 9c, d). Substantially more preference reversals can be observed when plotting the choice proportions as a function of frames, given a specific time limit (Fig. 9eh). A detailed analysis of framing effects and preference reversals for each group and treatment is found in Table 8 and Fig. 12 in Appendix 5. Note that the framing effects include preference reversals and preference shifts. Preference reversals occur more often for $\mathrm{G} 2(n=22)$ than for G1 $(n=32)$.

As before, we investigated the framing effect on the level of gambles in more detail. Figure 10 shows the choice proportions for choosing the gamble as a function of probabilities to keep the initial amounts (Fig. 10a-d) as well as a function of the initial amount given across the probabilities of keeping it (Fig. 10e-h). The left column presents the results for G1 $(n=32)$, and the right column the results for G2 $(n=22)$. For both groups, the framing effect is clearly preserved in the need conditions (solid vs filled bars with different gray shades) as well across the time limits. As in Experiment 1 , the probability of choosing the gamble depends on the probability of keeping. However, there is a striking difference between both groups when considering the choice proportions for choosing the gamble as a function of probabilities to keep the initial amounts (Fig. 10a-d). For G1, the smaller the probability of keeping the amount is the less often the gamble is chosen, but for $\mathrm{G} 2$ the pattern is reversed: the smaller the probability of keeping the amount is the more often the gamble is chosen. That is, G1 
replicates the pattern of Experiment 1, whereas G2 replicates the pattern of De Martino et al. (2006). The probability of choosing the gamble seems little to depend on the amount given (Fig. 10e-h). This is different from the results of Experiment 1 where we could observe a non-monotonic relation between the amounts given and the proportions for choosing the gamble.

Besides the different response behavior, we can only speculate in what way the two groups differ. Table 3 lists demographic information and the results of the selfassessment scores. Age is about the same and can be neglected. The female/male ratio is 1.3 in G1 and 0.58 in G2. The scores in each subtest are higher for G2 than for G1, but not dramatically (because there is no appropriate test, the standard error serves as benchmark). The most obvious difference between the two groups is the correlation between the scores of the subtest. All subtests are meant to measure risk attitude and should highly correlate. However, for G2, there is even a negative correlation between the life-situation test scores and the lottery test scores $(-0.26)$. Furthermore, the correlation between the lottery test scores and the self-assessment attitude score is very small. It seems that members of G2 are less consistent in their risk assessment.

\subsection{Summary and discussion}

The results of the second experiment partly support the previous findings. Overall, in a gain frame, the participants chose the sure option more often than in a loss frame. Time limits per se did not influence choice behavior (no statistically significant main effect; Table 2) but strengthened the framing effect (interaction between Frame and Time). Induced need had an effect on choice behavior and showed a statistically significant interaction with Frame: with increasing induced need participants became more risk taking in the gain frame.

A cluster analysis identified two groups. Different from Experiment 1, the groups were similar in their risk taking behavior (about the same proportions for choosing the gamble). However, they differed with respect to response strategies. Group G1 produced the same patterns as participants in Experiment 1. With increasing probabilities of keeping the initial amount, the choice proportion for choosing the gamble increased. The opposite pattern could be observed for G2. With increasing probabilities to keep the initial amount, the choice proportion to choose the gamble decreases - the same pattern as in De Martino et al.'s (2006) study. The risk selfassessment test gave little indication to what may have led to the different strategies. The choice proportions as a function of amount given were almost flat within a given frame. None of the amounts given seems to trigger a particular choice behavior as this was the case in Experiment 1 . That is, the different amounts given seem not to play a major role in choosing the gamble or not, and we do not stress it any further.

The analysis revealed further differences between both groups. Participants' choice behavior in G1 was influenced by Frame and Need (they were more risk seeking in the loss frame and with an induced need of 3600 points) whereas participants of G2 were influenced by Frame and Time. The interaction effects show that shorter time limits increased the framing effect in both groups and Need influenced the framing effect and the effect of time limits in G1. 


\section{Summary and concluding remarks}

How does induced need influence choice behavior? Do people become more risk taking when induced need is high rather than low, or are they more cautious when induced need is high? And does a time limit, in which the decision has to be made, reinforce the effect? To answer these questions, we conducted two experiments in which the decision-maker had a choice between a sure option and a risky gamble. The resulting choice proportions are often taken to indicate a person's risk preference. An abundance of studies, however, have shown that preference is not stable but depends on the context, the situation, or the frame in which the game is offered. In a gain frame, participants tend to choose sure options, whereas in a loss frame, participants tend to choose gambles.

First, both experiments revealed strong framing effects: decision-makers tend to choose the sure option in the gain frame and the gamble in the loss frame. In particular, the results corroborate those by De Martino et al. (2006), using a withinsubject design.

Second, time limits reinforced the framing effect. Both experiments replicate the results by Guo et al. (2015); Guo et al. (2017) in showing that time limits moderate the framing effect. When a gamble was presented in a gain frame with short time limits, the participants tend to choose the sure option even more often than when presented with long time limits. On the other hand, when a gamble was presented in a loss frame with short time limits, the participants tend to choose the risky option even more often, as compared to the long time limit condition. In contrast to previous studies (Guo et al. 2015; Guo et al. 2017) and Experiment 2, we also found a main effect for Time in Experiment 1: participants tend to be more risky under shorter deadlines. We can only speculate why this happened. In Experiment 1, we had less participants (19 with 960 trials per person) than in Experiment 2 (54 participants, each performing 624 trials). The analyses of individual differences have shown that participants in both groups in Experiment 1 were more homogeneous with respect to the time limit condition than those in Experiment 2. Thus, the main effect may have disappeared when considering the analyzing the entire sample. No analyses for individual differences had been performed in the forementioned studies.

Third, for the first time, we introduced induced need to investigate whether a target amount, i.e., the induced need to be reached, would modify the framing effect even further. For both experiments, we could observe a main effect for Need. When Need was high, participants tend to be more risk taking. In addition, we observed a moderator effect for Experiment 2. Here, the higher the induced need was, the more risk taking participants became in the gain frame. This may have been due to the overall higher need (points to reach during the game).

This latter finding differs from those of Diederich et al. (2018) who showed that the higher the need, i.e., number of people in need, the more risk-averse participants became. Obviously, the experimental paradigms (Asian disease vs risky game) and the need definitions (number of people affected vs number of points to obtain) are different that may be one reason for the discrepancy. Given that the constituents of the choice options (probabilities, outcome values, and gain/loss frames) were identical, we offer 
an additional reason for the different results: the decision-makers tend to be more riskseeking in risky decisions that affect their own needs (game scenario) and more riskaverse in decisions that affect other people's needs (Asian disease scenarios), that is, the decision context may play a role but also the perspective of the decision-maker. Stone and Allgaier (2008) and Stone et al. (2013) offer a framework that accounts for the contradictory effects of self-other risk taking. They propose that the direction of self-other discrepancy in risk preference depends on the social valence of taking risks. In domains where risk taking is viewed positively (such as gambling or playing lotteries), more risky options are selected when choosing for others than when choosing for oneself. By contrast, in domains where risk taking is viewed negatively (such as health), choices made for others are less risky than choices made for oneself. The framework may be also applicable for risky decisions regarding self/other needs. Further research is needed here.

According to the Stone-Geary utility model, we expected participants to be more risk seeking with increasing induced need. This was found in both experiments presented here.

For both experiments, we conducted more detailed analyses based on individual differences in choice behavior. Stated preferences on risky behavior to measure risk attitude were not informative for differentiating participants with respect to choice behavior. Therefore, we conducted cluster analyses over participants based on revealed choice behavior. The statistical analysis was repeated with each of these groups.

In Experiment 1, we identified two groups, $G_{\text {high }}$ with more risk taking participants than those in $G_{\text {low }}$. Obvious from the descriptive analysis-scatter diagram and choice frequency details-both groups differed with respect to quantities and patterns. However, both groups showed a similar overall pattern for choice probabilities as a function of probabilities for keeping the amount (increasing). The inference statistics showed effects in the same direction. For both groups, we could observe main effects for Frame, Time, and high Need. Furthermore, for both groups, we observed a statistically significant interaction between Frame and Time in the same direction as before. Additionally, for $G_{\text {high }}$, we found that Need tends to reduce the effect of Time.

In Experiment 2, the identified groups could not be described in terms of risk attitudes in general but rather by risk attitude depending on probabilities of keeping the amount. That is, for G1, the probability to choose the risky option increased as a function of increasing probabilities for keeping the amount whereas for G2, we observed the opposite patterns. For both groups (G1 and G2), we could observe a main effect of Frame on choice behavior but only for G1 a main effect for high Need and for G2 a main effect for Time. Furthermore, for G1, all interactions were statistically significant whereas for G2, only the Frame and Time interaction was significant. We did not propose any hypotheses with respect to individual differences and did not any personality tests besides risk attitudes and, therefore, we cannot offer any explanations for the observed differences. Further research may be needed here.

To conclude, framing risky gamble as gains and losses affect choice behavior, also in a within-subject design with many replications (quasi-psychophysical 
approach) as has been shown in many social sciences approaches (few decisions with many participants often with a between-subject design). Time limits and induced need moderate the framing effect. Short time limits tend to enhance the framing effect as does high induced need. That induced need is also subject to a framing effect that is important when allocating resources to needy people. The Stone-Geary utility framework suggested that decision-makings per se become more risk taking with increased need, regardless of the frame. This could indeed be observed (main effects) for the samples of both experiments and for three out of four subgroups identified in our study by cluster analysis.

Acknowledgements Open Access funding provided by Projekt DEAL. The research was supported by Deutsche Forschungsgemeinschaft Grant DFG FOR2104 (Need-based justice and distributive procedures), DI 506/13-1.

Open Access This article is licensed under a Creative Commons Attribution 4.0 International License, which permits use, sharing, adaptation, distribution and reproduction in any medium or format, as long as you give appropriate credit to the original author(s) and the source, provide a link to the Creative Commons licence, and indicate if changes were made. The images or other third party material in this article are included in the article's Creative Commons licence, unless indicated otherwise in a credit line to the material. If material is not included in the article's Creative Commons licence and your intended use is not permitted by statutory regulation or exceeds the permitted use, you will need to obtain permission directly from the copyright holder. To view a copy of this licence, visit http:// creativecommons.org/licenses/by/4.0/.

Data Availability Statement Materials and data are publicly archived on X-econ.org (http://x-econ.org/ xecon/\#!VerifyLink/0ba89e49-aa19-4261-a8ce-559ab12a9bcf).

\section{Appendices}

\section{Appendix 1}

The following questions to test the participants' risk attitudes were taken from the questionnaire of the "Sozio-Oekonomischen Panels 2009“

1. Human behavior is individual. Different people behave in different ways. How about You? How would you estimate your willingness to take risks in the following situations? Please choose an option on the scale. Value 0 means: "No willingness for taking risks". Value 5 means: "Willingness for taking high risks". You can adjust your choice with the values between 0 and 5 . How is your willingness to take risks...

\begin{tabular}{|c|c|c|c|c|c|c|}
\hline & 0 & 1 & 2 & 3 & 4 & 5 \\
\hline ... while car driving? & & & & & & \\
\hline ... when you invest money? & & & & & & \\
\hline ... in your free time; during sports? & & & & & & \\
\hline ... regarding your career? & & & & & & \\
\hline ... regarding your health? & & & & & & \\
\hline when you trust in unknown people? & & & & & & \\
\hline
\end{tabular}


2. Consider what you would do in the situation below: Imagine you would win 100,000 €in a lottery. Immediately after receiving the money, you get an offer for the following lottery: You have the chance to double your stake. But there is the same chance to lose the half of it. You can place all of your 100,000 €or less in the increments below. It is also possible to reject the lottery.

How much would you bet?

Everything. The whole $100,000 €$
$80,000 €$
$60,000 €$
$40,000 €$
$20,000 €$

3. How do you assess yourself? Are you a risk-averse person or are you a riskseeking person? Please choose an option on the scale. Value 0 means: "no willingness for taking risks". Value 5 means: "willingness for taking high risks".

\begin{tabular}{|l|l|l|l|l|l|l|}
\cline { 2 - 8 } My willingness for taking risks & 0 & 1 & 2 & 3 & 4 & 5 \\
\cline { 2 - 8 } & & & & & & \\
\hline
\end{tabular}

\section{Appendix 2}

For quantifying the framing effect across all games but separate for each need and time limit condition, the following procedure was carried out. For each participant and each game (four replications) the choice proportions to choose the gamble were determined. The difference between choice proportions in corresponding gain/ loss choice games, $\mathrm{P}\left(\right.$ gamble $\left._{G}\right)$ and $\mathrm{P}\left(\right.$ gamble $\left._{L}\right)$, respectively, served, with $\mid \mathrm{P}\left(\right.$ gamble $\left._{G}\right)-\mathrm{P}\left(\right.$ gamble $\left._{L}\right) \mid \neq 0$, as an indicator for a framing effect. In particular, when $\mid \mathrm{P}\left(\right.$ gamble $\left._{G}\right)-\mathrm{P}\left(\right.$ gamble $\left._{L}\right) \mid>0.5$ a preference reversal has occurred. In a second step, the number of framing effects was related to the number of games (trials). A Friedman two-way analysis of variance by ranks showed no differences in the distribution of framing effects and preference reversals between all three need conditions under any time constraints condition. A Wilcoxon signed rank test showed differences of choice behavior depending on time pressure within the need treatments: Framing effects occurred more often under the 1-s time limit for Need (0) $(\mathrm{Z}=-2.488, p<0.05)$ and for Need (3500) $(\mathrm{Z}=-2.247, p<0.05)$. Statistically significant more preference reversals could be observed in the 1-s time limit condition than in the 3-s limit condition for each need condition (Need (0): $Z=-3.203, p<0.01 ; \quad$ Need (2500): $Z=-3.431, p<0.01 ; \quad$ Need $\quad(3500)$ : $\mathrm{Z}=-2.641 ; p<0.01$ ) (Fig. 11).

Using the same procedure, Table 4 shows the number of framing effects and preference reversals (in parentheses) for each group and treatment. 

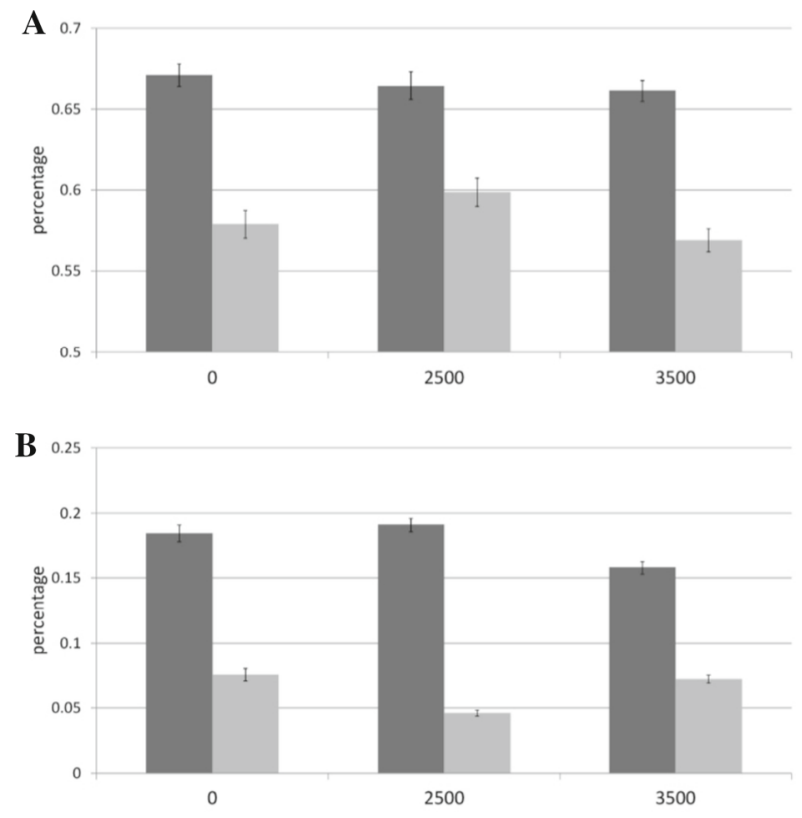

Fig. 11 Experiment 1: relative number of framing effects (a) and preference reversals (b) across participants. Note that preference reversals are a subset of framing effects. Dark gray columns: 1-s time condition; light gray columns: 3 -s time condition

Table 4 Experiment 1: number of framing effects (preference reversals) for both groups and each condition

\begin{tabular}{llllll}
\hline Group & Need & GainlTime & LosslTime & 3 slFrame & 1 slFrame \\
\hline $\mathrm{G}_{\text {high }}$ & 0 & $13(8)$ & $9(0)$ & $15(1)$ & $15(9)$ \\
& 2500 & $14(6)$ & $9(0)$ & $13(0)$ & $16(8)$ \\
& 3500 & $12(0)$ & $11(0)$ & $13(0)$ & $16(1)$ \\
$\mathrm{G}_{\text {low }}$ & 0 & $15(0)$ & $8(1)$ & $14(0)$ & $16(1)$ \\
& 2500 & $13(4)$ & $12(1)$ & $15(1)$ & $16(4)$ \\
& 3500 & $10(4)$ & $11(3)$ & $14(2)$ & $16(5)$ \\
\hline
\end{tabular}

GainlTime means gain frame condition given both time limit conditions. 3-s|Frame means 3-s time limit given both frames

\section{Appendix 3}

Results of the self-assessment risk questionnaire for each of the 19 participants and group membership according to clustering (Table 5). 
Table 5 Experiment 1: individual scores of the sub-scales for each of the participants

\begin{tabular}{|c|c|c|c|c|c|c|c|c|c|c|c|c|}
\hline \multirow[t]{2}{*}{$\mathrm{P}$} & \multirow{2}{*}{$\begin{array}{l}\text { Self- } \\
\text { rated } \\
\text { risk } \\
\text { attitude }\end{array}$} & \multirow{2}{*}{$\begin{array}{l}\text { Willing- } \\
\text { ness in } \\
\text { Betting }\end{array}$} & \multicolumn{7}{|c|}{ Behavior } & \multirow{2}{*}{$\begin{array}{l}\text { Risk } \\
\mathrm{R}\end{array}$} & \multirow{2}{*}{$\begin{array}{l}\mathrm{H}-\mathrm{Cl} . \\
\mathrm{G}\end{array}$} & \multirow[t]{2}{*}{$\mathrm{K}-\mathrm{Cl}$} \\
\hline & & & M & $\mathrm{L}$ & $\mathrm{H}$ & $\mathrm{D}$ & $\mathrm{C}$ & $\mathrm{T}$ & Sum & & & \\
\hline 1 & 2 & 1 & 0 & 3 & 0 & 0 & 1 & 5 & 9 & 2 & 2 & 2 \\
\hline 2 & 1 & 1 & 2 & 3 & 1 & 1 & 3 & 0 & 9 & 2 & 1 & 1 \\
\hline 3 & 3 & 0 & 1 & 3 & 2 & 1 & 1 & 0 & 8 & 2 & 2 & 2 \\
\hline 4 & 1 & 1 & 2 & 2 & 1 & 1 & 3 & 3 & 12 & 1 & 2 & 2 \\
\hline 5 & 2 & 1 & 2 & 1 & 1 & 4 & 1 & 3 & 12 & 1 & 2 & 2 \\
\hline 6 & 2 & 2 & 3 & 5 & 2 & 1 & 4 & 1 & 16 & 1 & 1 & 1 \\
\hline 7 & 2 & 0 & 1 & 3 & 1 & 1 & 3 & 1 & 10 & 2 & 2 & 2 \\
\hline 8 & 1 & 0 & 1 & 2 & 2 & 0 & 3 & 0 & 8 & 2 & 2 & 2 \\
\hline 9 & 1 & 1 & 3 & 2 & 0 & 0 & 1 & 1 & 7 & 2 & 3 & 1 \\
\hline 10 & 3 & 0 & 3 & 4 & 1 & 1 & 2 & 1 & 13 & 1 & 1 & 1 \\
\hline 11 & 4 & 2 & 3 & 3 & 0 & 1 & 4 & 0 & 11 & 1 & 3 & 1 \\
\hline 12 & 2 & 3 & 3 & 3 & 1 & 1 & 3 & 1 & 12 & 1 & 2 & 2 \\
\hline 13 & 1 & 1 & 1 & 3 & 0 & 0 & 3 & 0 & 9 & 2 & 1 & 1 \\
\hline 14 & 3 & 1 & 3 & 4 & 1 & 1 & 5 & 1 & 15 & 1 & 1 & 1 \\
\hline 15 & 1 & 2 & 2 & 3 & 0 & 1 & 1 & 0 & 7 & 2 & 1 & 1 \\
\hline 16 & 2 & 2 & 1 & 4 & 3 & 2 & 2 & 3 & 15 & 1 & 2 & 2 \\
\hline 17 & 1 & 2 & 2 & 2 & 1 & 2 & 0 & 1 & 8 & 2 & 2 & 2 \\
\hline 18 & 3 & 0 & 2 & 2 & 5 & 1 & 5 & 5 & 20 & 1 & 1 & 1 \\
\hline 19 & 2 & 1 & 1 & 3 & 1 & 1 & 3 & 1 & 10 & 2 & 2 & 2 \\
\hline
\end{tabular}

Sum refers to the sum of the six sub-scale scores describing risky behavior in daily life (M: money; L: leisure; H: health: D: driving; C: career; T: trust). The median of the sum serves to divide the sample into two groups with R 1 referring to the lower scores and R 2 to the higher scores. H-Cluster and K-Cluster refer to the clustering results with hierarchical and k-means methods, respectively

\section{Appendix 4}

Linear mixed effects model (statistic software R (version 3.4.2), method: LMER) separate for group 1 and group 2 (Tables 6, 7). 


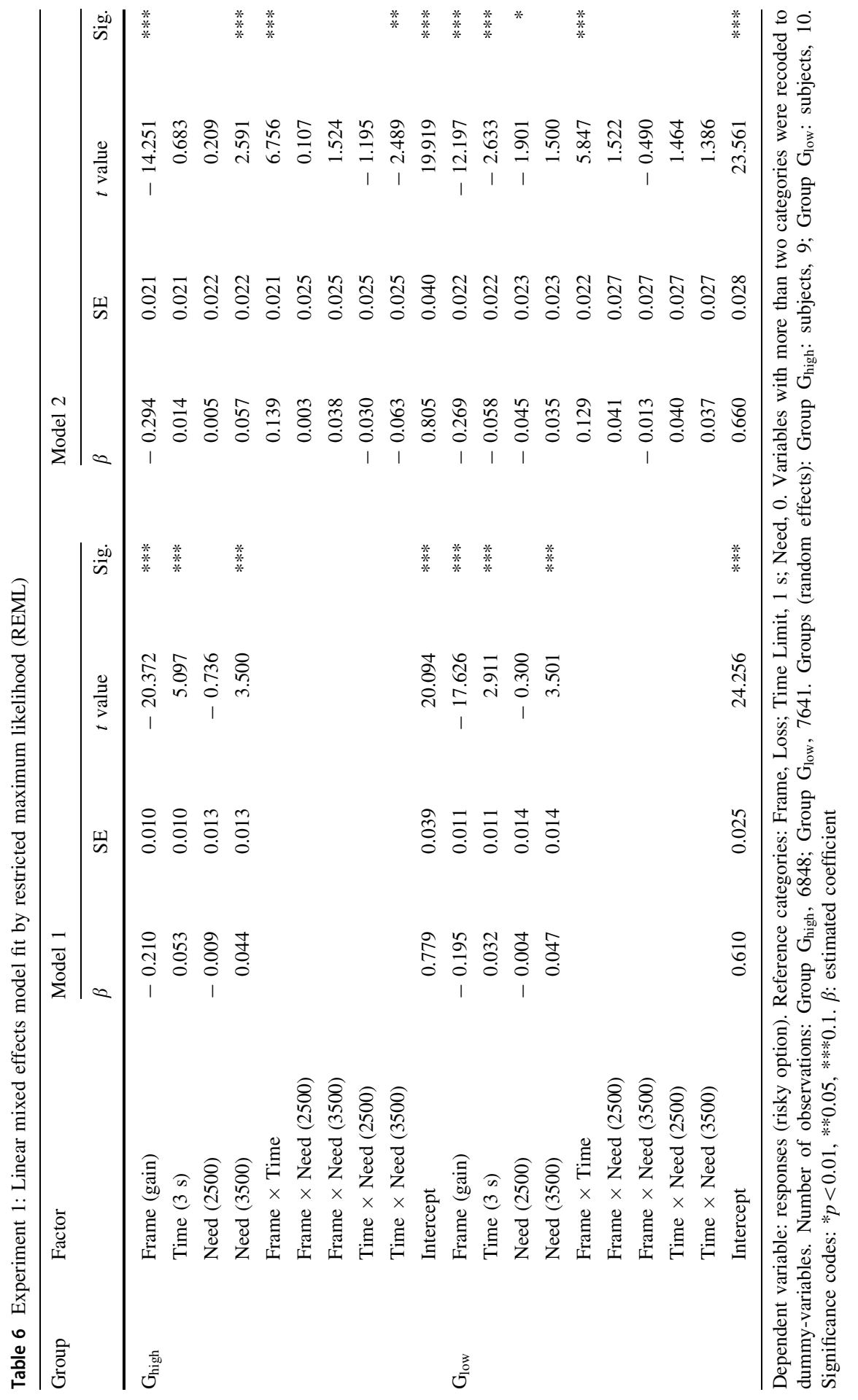




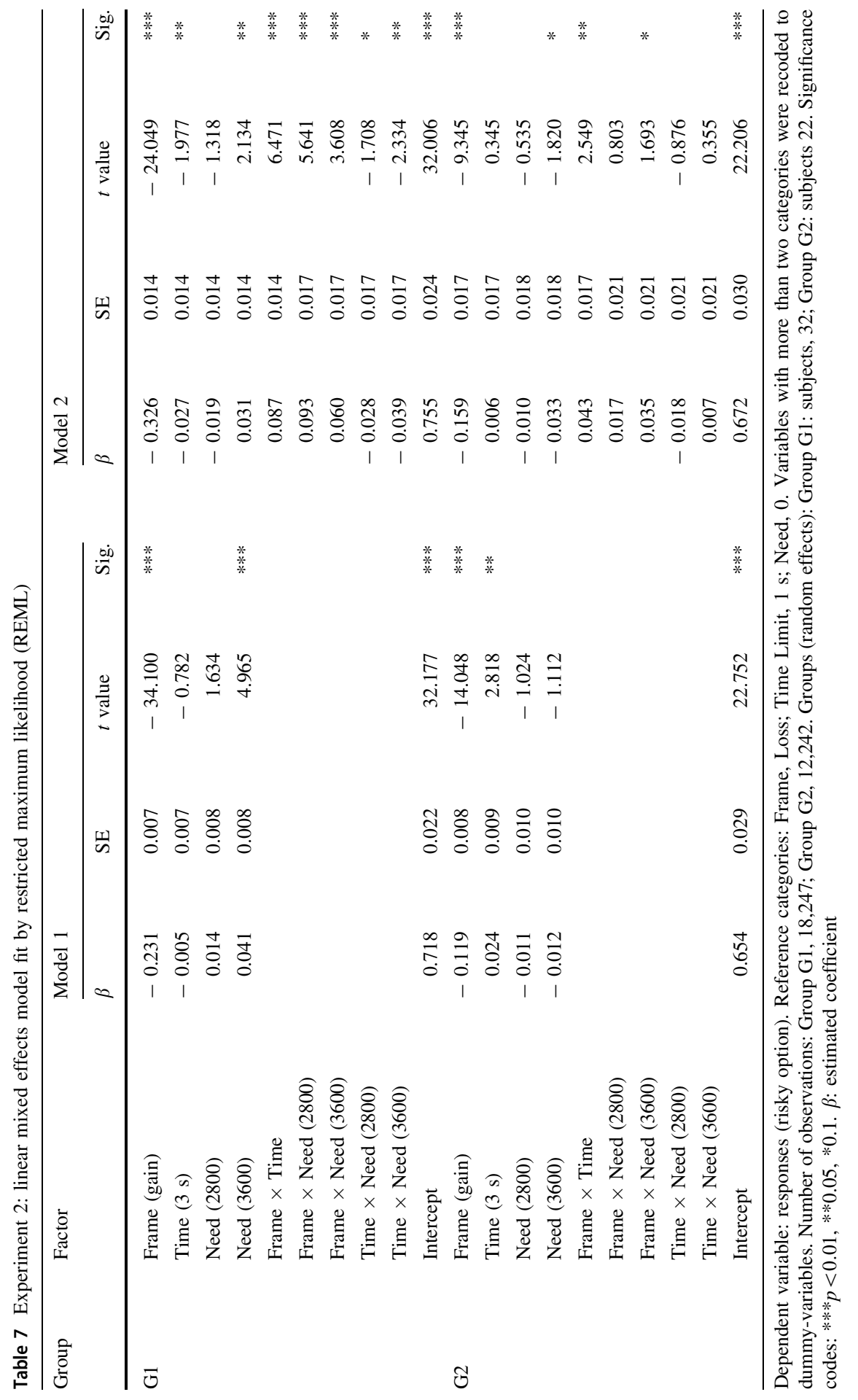




\section{Appendix 5}

For quantifying the framing effect across all games but separate for each need and time limit condition, the same procedure as in Experiment 1 was carried out. Friedman's two-way analysis of variance by ranks shows that there are no differences in the distribution of framing effects and preference reversals between all three need conditions under time pressure (1-s response time). Without time pressure $(3 \mathrm{~s})$ the participants showed both more framing effects (2800: $F_{R}=0.380 ; p<0.05$, and 3600: $F_{R}=0.426 ; p<0.05$ compared to 0 need condition) and preference reversals (2800: $F_{R}=0.500 ; p<0.01$, and 3600: $F_{R}=0.500 ; p<0.01$ compared to 0 need condition). A Wilcoxon signed rank test shows differences of choice behavior depending on time pressure within the
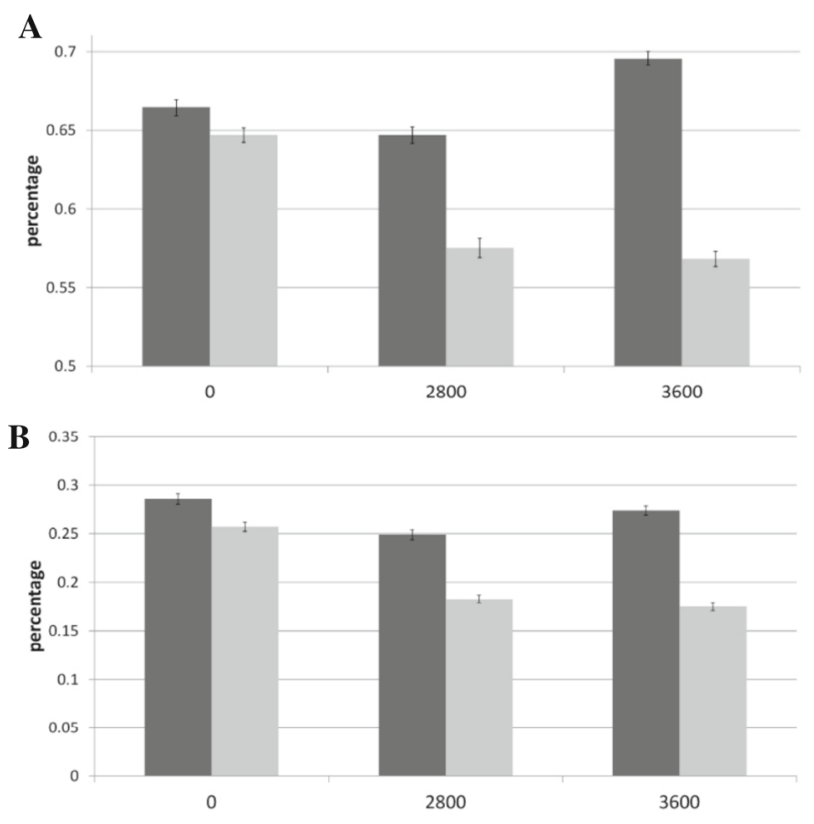

Fig. 12 Experiment 2: relative number of framing effects (a) and preference reversals (b) across participants. Note that preference reversals are a subset of framing effects. Dark gray columns: 1-s time condition; light gray columns: 3 -s time condition

Table 8 Experiment 2: number of framing effects (preference reversals) for both groups and each condition. GainlTime means gain frame condition given both time limit conditions. 3-sIFrame means 3-s time limit given both frames

\begin{tabular}{llllll}
\hline Group & Need & GainlTime & LosslTime & 3 slFrame & 1 sIFrame \\
\hline G1 & 0 & $10(1)$ & $8(4)$ & $16(7)$ & $16(4)$ \\
& 2800 & $7(0)$ & $7(1)$ & $16(5)$ & $16(4)$ \\
& 3600 & $6(0)$ & $8(2)$ & $16(5)$ & $16(7)$ \\
G2 & 0 & $11(0)$ & $10(0)$ & $12(6)$ & $15(8)$ \\
& 2800 & $11(0)$ & $12(3)$ & $13(5)$ & $13(7)$ \\
& 3600 & $11(2)$ & $10(2)$ & $11(5)$ & $13(8)$ \\
\hline
\end{tabular}


need treatments: framing effects occurred more often under time pressure in 2800 $(Z=-2.733, p<0.01)$ and 3600 condition $(Z=-4.079, p<0.01)$. There are significant more preference reversals under time pressure in the following need conditions (2800: $Z=-2.565, p<0.01$; 3600: $Z=-3.407$; $p<0.01$ ) (Fig. 12; Table 8).

\section{Appendix 6}

Results of the risk self-assessment test summarized across 49 participants. Figure 13 shows the frequency distributions of the three subtests and the overall scores.
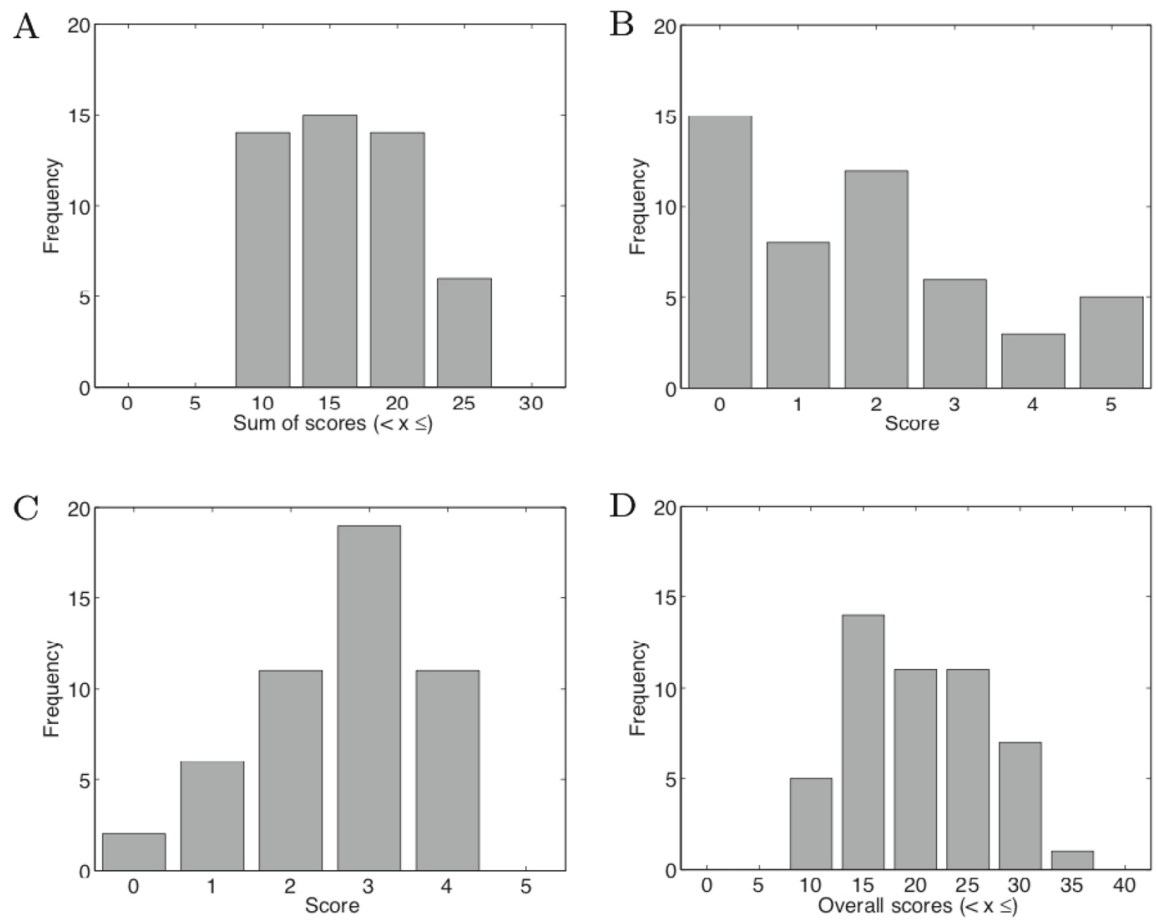

Fig. 13 Experiment 2: frequency distributions of scores obtained in three subtests and overall scores based on 49 participants. a Distribution of sum of scores for six items referring to risky behavior in daily life situations. b Distribution of scores for the willingness to bet in a lottery. $\mathbf{c}$ Distribution of scores for risk self-rating. d Distribution of overall scores 


\section{Appendix 7}

To test for possible sequence effects we performed auto-correlation for each experiment. Across all participants the number of risky choices was counted for each trial $i$, separately for each experimental block. A Pearson correlation between the trials of the first half and the trials of the last half of each block was calculated. None of the correlations showed a significant result. Participants did not become more risk seeking at the end of the blocks (Tables 9, 10).

Table 9 Test for sequential effects for Experiment 1

\begin{tabular}{|c|c|c|c|c|c|c|c|c|}
\hline \multirow[t]{2}{*}{ Trial } & \multicolumn{2}{|c|}{ Block 1} & \multicolumn{2}{|l|}{ Block 2} & \multicolumn{2}{|l|}{ Block 3} & \multicolumn{2}{|l|}{ Block 4} \\
\hline & $1-40$ & $40-80$ & $81-120$ & $121-160$ & $161-200$ & $201-240$ & $241-280$ & $281-320$ \\
\hline \multicolumn{9}{|l|}{ Need (2500) } \\
\hline Mean & 9.7 & 9.5 & 9.1 & 8.5 & 9.6 & 9.3 & 8.9 & 8.2 \\
\hline Pearson correlation & \multirow{2}{*}{\multicolumn{2}{|c|}{-0.052}} & \multirow{2}{*}{\multicolumn{2}{|c|}{-0.211}} & \multirow{2}{*}{\multicolumn{2}{|c|}{0.114}} & \multirow{2}{*}{\multicolumn{2}{|c|}{-0.087}} \\
\hline Need (3500) & & & & & & & & \\
\hline Mean & 9.4 & 10.6 & 9.6 & 9.9 & 10.6 & 10.1 & 9.2 & 9.5 \\
\hline Pearson correlation & & 0.009 & & 0.095 & & 0.083 & & 0.049 \\
\hline
\end{tabular}

The displayed Pearson correlation describes the correlation between the first 40 trials and the last 40 trials of each block. The displayed mean is the mean of the sum of risky choices per trial across all participants and within the respective block

Table 10 Test for sequential effects for Experiment 2

\begin{tabular}{|c|c|c|c|c|c|c|c|c|}
\hline \multirow[t]{2}{*}{ Trial } & \multicolumn{2}{|l|}{ Block 3} & \multicolumn{2}{|l|}{ Block 4} & \multicolumn{2}{|l|}{ Block 5} & \multicolumn{2}{|l|}{ Block 6} \\
\hline & $209-260$ & $261-312$ & $313-364$ & $365-416$ & $417-468$ & $469-520$ & $521-572$ & $573-624$ \\
\hline \multicolumn{9}{|l|}{ Need (2800) } \\
\hline Mean & 15.5 & 15.8 & 15.6 & 14.8 & 16.3 & 16.4 & 17.3 & 17.3 \\
\hline $\begin{array}{l}\text { Pearson } \\
\text { correlation }\end{array}$ & & -0.083 & & -0.095 & & -0.1 & & 0.107 \\
\hline \multicolumn{9}{|l|}{ Need (3600) } \\
\hline Mean & 17 & 16.9 & 16.8 & 16.8 & 16.3 & 16.3 & 15.6 & 16.3 \\
\hline $\begin{array}{l}\text { Pearson } \\
\text { correlation }\end{array}$ & & 0.031 & & -0.036 & & 0.075 & & -0.251 \\
\hline
\end{tabular}

The displayed Pearson correlation describes the correlation between the first 52 trials and the last 52 trials of each block. The displayed mean is the mean of the sum of risky choices per trial across all participants and within the respective block 


\section{References}

Albers, W. (2001). Prominence theory as a tool to model boundedly rational decisions. In G. Gigerenzer \& R. Selten (Eds.), Bounded rationality: The adaptive toolbox (pp. 297-317). Cambridge: The MIT Press.

Bateman, I., Dent, S., Peters, E., Slovic, P., \& Starmer, C. (2007). The affect heuristic and the attractiveness of simple gambles. Journal of Behavioral Decision Making, 20(4), 365-380. Referenz einfügen.

Deaton, A., \& Muellbauer, J. (1980). Economics and consumer behavior. Cambridge: Cambridge University Press.

De Martino, B., Kumaran, D., Seymour, B., \& Dolan, R. J. (2006). Frames, biases, and rational decisionmaking in the human brain. Science, 313(5787), 684-687.

Deutsch, M. (1975). Equity, equality, and need: What determines which value will be used as the basis of distributive justice? Journal of Social Issues, 31(3), 137-149.

Diederich, A. (2003). Decision making under conflict: Decision time as a measure of conflict strength. Psychonomic Bulletin and Review, 10(1), 167-176.

Diederich, A., \& Busemeyer, J. R. (2006). Modeling the effects of payoff on response bias in a perceptual discrimination task: Bound-change, drift-rate-change, or two-stage-processing hypothesis. Perception and Psychophysics, 68(2), 194-207.

Diederich, A., Wyszynski, M., \& Ritov, I. (2018). Moderators of framing effect in variations of the Asian Disease problem: Time constraint, need, and disease type. Judgment and Decision Making, 13(6), 529-546.

Gamliel, E., \& Peer, E. (2006). Positive versus negative framing affects justice judgments. Social Justice Research, 19(3), 307-322.

Gamliel, E., \& Peer, E. (2010). Attribute framing affects the perceived fairness of health care allocation principles. Judgment and Decision Making, 5(1), 11-20.

Geary, R. C. (1950). A note on "A constant-utility index of the cost of living". The Review of Economic Studies, 18(1), 65-66.

Guo, L., Trueblood, J. S., \& Diederich, A. (2015). A dual-process model of framing effects in risky choice. In COGSCI 2015, Pasadena.

Guo, L., Trueblood, J. S., \& Diederich, A. (2017). Thinking fast increases framing effects in risky decision making. Psychological Science, 28(4), 530-543.

Kahneman, D. (2011). Thinking, fast and slow. New York: Macmillan.

Kahneman, D., \& Tversky, A. (1979). Prospect theory: An analysis of decision under risk. Econometrica: Journal of the Econometric Society, 47, 263-291.

Kahneman, D., \& Tversky, A. (2000). Choices, values, and frames. In D. Kahneman \& A. Tversky (Eds.), Choices, values, and frames (pp. 1-17). Cambridge: Cambridge University Press.

Kittel, B., \& Traub, S. (2020). Need-based distributional justice: An interdisciplinary perspective. Heidelberg: Springer.

Konow, J. (2001). Fair and square: the four sides of distributive justice. Journal of Economic Behavior and Organization, 46(2), 137-164.

Konow, J. (2003). Which is the fairest one of all? A positive analysis of justice theories. Journal of Economic Literature, 41(4), 1188-1239.

Kühberger, A. (1998). The influence of framing on risky decisions: A meta-analysis. Organizational Behavior and Human Decision Processes, 75(1), 23-55.

Kühberger, A., Schulte-Mecklenbeck, M., \& Perner, J. (1999). The effects of framing, reflection, probability, and payoff on risk preference in choice tasks. Organizational Behavior and Human Decision Processes, 78(3), 204-231.

Lamm, H., \& Schwinger, T. (1983). Need consideration in allocation decisions: Is it just? The Journal of Social Psychology, 119(2), 205-209.

Lopes, L. (1983). Some thoughts on the psychological concept of risk. Journal of Experimental Psychology: Human Perception and Performance, 9(1), 137-144.

Pashler, H., \& Wagenmakers, E. (2012). Editors' introduction to the special section on replicability in psychological science: A crisis of confidence? Perspectives on Psychological Science, 7(6), 528-530.

Core Team, R. (2018). R: A language and environment for statistical computing. Vienna: R Foundation for Statistical Computing. 
Sabbagh, C., \& Schmitt, M. (2016). Handbook of social justice theory and research. New York: Springer. Schwinger, T., \& Lamm, H. (1981). Justice norms in allocation decisions: Need consideration as a function of resource adequacy for complete need satisfaction, recipients' contributions, and recipients' interpersonal attraction. Social Behavior and Personality, 9(2), 235-241.

Stone, E. R., \& Allgaier, L. (2008). A social values analysis of self-other differences in decision making involving risk. Basic and Applied Social Psychology, 30(2), 114-129.

Stone, E. R., Choi, Y., de Bruin, W. B., \& Mandel, D. R. (2013). I can take the risk, but you should be safe: Self-other differences in situations involving physical safety. Judgment and Decision Making, $8(3), 250$.

Stone, R. (1954). Linear expenditure systems and demand analysis: An application to the pattern of British demand. The Economic Journal, 64(255), 511-527.

TNS Infratest Sozialforschung (2012). Methodenbericht zum Befragungsjahr 2009 (Welle 26) des Soziooekonomischen Panels. In SOEP Survey Papers 70: Series B. Berlin: DIW/SOEP.

Törnblom, K. Y. (1988). Positive and negative allocations: A typology and a model for conflicting justice principles. Advances in Group Processes, 5, 141-168.

Tversky, A., \& Kahneman, D. (1981). The framing of decisions and the psychology of choice. Science, 211(4481), 453-458.

Von Neumann, J., \& Morgenstern, O. (1947). Theory of games and economic behavior, 2nd rev. ed. Princeton: Princeton University Press.

Publisher's Note Springer Nature remains neutral with regard to jurisdictional claims in published maps and institutional affiliations. 